\title{
A Suggestion of Korean Names for the Orders and Families Included in the APG III Classification System
}

\author{
Yoonkyung Lee, Jongduk Jung and Sangtae Kim*
}

Department of Biology, Sungshin Women's University, Seoul 01133, Korea

(Received 13 August 2015; Revised 8 September; Accepted 10 September 2015)

\section{APG III 분류체계의 목명 및 과명 국문화에 대한 제안 \\ 이윤경 · 정종덕 · 김상태* \\ 성신여자대학교 생물학과}

\begin{abstract}
With the development of the internet and international agreements such as the Convention on Biological Diversity (CBD) and the Convention on International Trade in Endangered Species (CITES), Korean researchers frequently encounter scientific names of foreign species, and these are named on a case-by-case basis in Korean without any standard naming method. Therefore, standard Korean names for entire orders and families in the world are required for better communications in Korea. However, there have been no comprehensive discussions of the standardization of Korean names for the orders and families found in the world. In this study, we 1) compare the Korean names of orders and families in the references, 2) discuss naming methods in Korean for foreign taxa, and 3) then suggest standard Korean names for the orders and families in the APG III, which is an up-to-date angiosperm classification system. This study will be a starting point for the national standardization of Korean names for orders and families found throughout the world.
\end{abstract}

Keywords: APG III system, Cronquist system, Korean name, standard name

적 요: 인터넷의 발달과 생물다양성협약(Convention on Biological Diversity; CBD), 멸종위기에 처한 야생 동식 물 종의 국제거래에 관한 협약(Convention on International Trade in Endangered Species; CITES) 등으로 국내 자 생 식물들과 함께 전 세계 식물들의 정보를 국내에서도 빈번하게 접하고, 또한 이를 이용하고 있다. 이에 현재 전 세계적으로 가장 널리 사용되고 있는 APG III 분류체계에서 채택한 과명 및 목명 전체에 대한 국문의 표준 화가 요구되지만, 지금까지 이들에 대한 통일적 국문화에 대한 논의는 부족하였다. 이에 본 연구에서는 1) 기존 의 국내 자생 분류군들이 속한 과명 및 목명을 종합하여 비교하고, 2) 국내에 분포하지 않는 종들이 속하는 과 명과 목명의 국문화에 대하여 현재까지 이루어진 방법들을 고찰하였으며, 이를 바탕으로 3) 본 연구자들이 판단 한 타당한 기준에 의해 APG III 분류체계 상의 과와 목에 대한 국명의 표준안을 제안하였다. 본 연구에서 제안 한 목과 과에 대한 국명들은 향후 전문가 그룹의 논의를 거쳐 공표될 국가표준안의 기초를 제공할 것이다.

주요어: APG III 분류체계, Cronquist 분류체계, 국명, 표준명

지난 이십여 년 간 식물의 계통을 추론하는 이론과 실 험적 토대가 비약적으로 발전함에 따라 다수의 식물분류 학자들은 공동으로 피자식물 분류체계인 Angiosperm

*Author for correspondence: amborella@sungshin.ac.kr

http://www.pltaxa.or.kr

Copyright (C) 2015 the Korean Society of Plant Taxonomists
Phylogeny Group (APG, 1998) 체계를 발표하였다. 이후 APG II (APG, 2003), APG III (APG, 2009)가 차례로 발표 되어 개정되었고, 이후 부분적인 수정이 이루어 졌을 뿐, 최초 발표된 체계에서 큰 변화는 없다. 현재 분류군 인식 에 대한 미소한 변화들은 새로운 분자계통학적 연구들이 추가될 때마다 Angiosperm Phylogeny Web site (Stevens, 2015; 이하 APW로 표기)를 통해 종합되어 주기적으로 분 류체계에 반영되고 있으며, 2015년 4월에는 APW version 
14 가 발표된 바 있다. 최근에 발간된 거의 모든 식물분류 학 교과서는 $\mathrm{APG}$ 분류체계를 받아들여 $\mathrm{APG}$ 분류체계의 순서에 의해 피자식물 분류군들을 서술하고 있고(예, Judd et al., 2008; Simpson, 2010), 현재 APW를 통해 전 세 계의 식물학자들과 일반인들은 연구와 교육을 위하여 최 신 분류체계를 보다 쉽게 접할 수 있게 되었다.

국내에 자생하는 식물들의 과명에 대한 국명들은 여러 식물 도감들 및 검색표(Chung et al., 1937; Chung et al., 1949; Pak, 1949; Chung, 1957; Lee, 1989; W. T. Lee, 1996a, b; Y. N. Lee 1996)에서 종합된 바 있다. 위의 문헌들을 바 탕으로 국가표준식물목록(Korean Plant Name Index; Korea National Arboretum and The Plant Taxonomic Society of Korea, 2007; 이하 KPNI로 표기)에서는 자생식물과 귀 화식물 등 총 205 과 1,142 속 4,881종의 표준명칭을 제시 한 바 있다. KPNI에는 도입종과 널리 알려진 재배식물의 원종도 포함되어 있으며, 피자식물들의 배열 순서는 Engler (1964) 분류체계를 따르고 있다. 이와 비슷한 시기 에 발표된 속식물지(Genera of Vascular Plants of Korea; Park, 2007; 이하 GVPK로 표기)에서는 217과 1,045속 3,034 종의 국명을 포함하고 있으며, Cronquist (1981) 분류 체계를 따르고 있다. 보다 최근에 산림청 국립수목원에 서는 KPNI를 확장하여 재배식물들을 포함한 버전이 웹 사이트를 통해 배포되고 있고(Korea National Arboretum, 2014; 이하 2014년 6월 30일 버전을 KPNI-WEB으로 표기 ), 환경부 국립생물자원관에서는 $\mathrm{GVPK}$ 를 바탕으로한 국 가 생물종 목록집의 관속식물편[National List of Species of Korea (Vascular Plants); National Institute of Biological Resources, 2011; 이하 NLSK로 표기]을 편찬하여 현재까 지 KPNI, GVPK, NLSK는 과명과 목명을 포함한 한반도 피자식물의 국명 기준으로 널리 사용되고 있다.

현재 인터넷의 발달과 생물다양성협약(Convention on Biological Diversity; CBD), 멸종위기에 처한 야생 동식물 종 의 국제거래에 관한 협약(Convention on International Trade in Endangered Species; CITES) 등으로 국내 자생 식물들과 함 께 전 세계 식물들의 정보를 국내에서도 빈번하게 접하고,
또한 이를 이용하고 있다. 이에 국내에서의 원활한 정보교 환을 위하여 빈번히 사용되는 외국 종들에 대한 국문화가 요구되고 있다. 각각의 종에 대한 국문의 표준화 이전에 선 행되어야 할 것은 현재 전 세계적으로 가장 널리 사용되고 있는 APG III (APG, 2009) 분류체계에서 채택한 과명 및 목 명 전체에 대한 국문의 표준화이다. 그러나 현재까지 국내 에 분포하지 않는 분류군들의 과명 및 목명에 대하여 필요 에 따라 정확한 기준 없이 수시로 국문화가 이루어 졌을 뿐, 전체 과명과 목명의 통일적 국문화에 대한 논의는 부족하 였다. $\mathrm{APG}$ 체계는 분자계통학적 연구 결과의 집약으로 수 립되었고(APG, 1998; APG, 2003; APG, 2009), 목과 과 수준의 상위 분류군들의 인식은 계통학적 자료가 포화단계에 이 르러 앞으로 큰 틀에서의 변화는 없으리라 예상된다.

본 연구의 목표는 안정된 분류체계인 $\mathrm{APG}$ 분류체계 상 의 모든 목 및 과명에 대한 국문 명칭의 표준화 안을 제시 하는 것으로 이는 국내에 소개되지 않은 신종/미기록종/도 입종의 추가, 재배식물의 도입, 생물자원의 국제교류 등 필 요시 해당 분류군에 대하여 그때 그때 새로운 국문 목 및 과명을 제시하여야 하는 번거로움과 이에 따른 혼란을 막 아주어 국가생물자원의 효율적인 관리에 도움을 주리라 생각된다. 이에 본 연구에서는 1) 기존의 국내 자생 분류군 들이 속한 과명 및 목명을 종합하여 비교하였고, 2) 국내에 분포하지 않는 종들이 속하는 과명과 목명의 국문화에 대 하여 현재까지 이루어진 방법들을 고찰하였으며. 이를 바 탕으로 3) 본 연구자들이 판단한 타당한 기준에 의해 APG III 분류체계 상의 과와 목에 대한 국명의 표준안을 제안하 였다. 아울러 APG III 분류체계를 현재 국내 국가기관들의 종정보 관리에 가장 많이 사용하고 있는 Cronquist 분류체 계 (Cronquist, 1981)와 비교하여 APG III 체계 상의 국내 자 생 분류군들에 대한 인식의 변화를 종합하여 제시하였다.

\section{재료 및 방법}

본 연구에서는 APG III (APG, 2009) 분류체계를 바탕으 로 이의 발표 후 사소한 수정이 반영된 APW의 version 14

Box 1. 과의 국문화 방법

1. 과의 기준 속(type genus)이 국내에 분포할 때 $\rightarrow$ 기준속의 국명에 의해 국문 과명을 표기

예) Phyllanthaceae (여우주머니과): 기준속인 Phyllanthus (여우주머니속)이 우리나라에 존재 Linderniaceae (밭둑외풀과): 기준속인 Lindernia (밭둑외풀속)이 우리나라에 존재

2. 과의 기준속이 국내에 분포하지 않을 때 $\rightarrow$ 아래 세 가지 방법 중 하나를 채택

2-1. 기준속 외의 속이 국내에 분포하면 그 속명을 이용하여 과명 표기

예) Melanthiaceae (여로과): 우리나라에는 이 과에 속하는 Veratrum (여로속)은 분포하지만 기준속인 Melanthium은 없음 Colchicaceae (애기나리과): 우리나라에는 이 과에 속하는 Disporum (애기나리속)이 분포하지만 기준속인 Colchica는 없음

2-2. 해당 분류군이 한자권 국가에서 있을 때 과의 한자어를 국문으로 읽는 소리로 표기

예) Rhizophoraceae (홍수과): 중국식물지의红樹科를 도입 Melastomataceae (야모란과): 중국식물지의 野牡丹科 를 도입

2-3. 기준속을 발음대로 표기 (향후 분류군의 특성을 반영한 한글 이름을 새로 명명 가능)

예) Amborellaceae (암보렐라과): 기준속인 Amborella를 발음대로 표기

Lactoridaceae (락토리스과): 기준속인 Lactoris를 발음대로 표기 
(Stevens, 2015) 분류체계를 이용하였다. 본 연구에서는 기 존에 국내 식물 및 재배종의 리스트가 정리된 바 있는 KPNI (Korea National Arboretum and The Plant Taxonomic Society of Korea, 2007), GVPK (Park, 2007), Kim et al. (2008), NLSK (National Institute of Biological Resources, 2011), KPNI-WEB (Korea National Arboretum, 2014) 의 다 섯 문헌에서 제시된 과명과 국문 과명들을 Microsoft Access 프로그램에 의해 데이터베이스화 하여 이들을 상 호 비교하고 검토하였다.

본 연구에서는 위의 다섯 문헌들은 국가기관에서의 배
포 또는 학술 논문으로 국문 과명들은 지금까지 널리 사 용되어 왔으므로 국문 변동에 의한 혼란을 피하고자 국문 화의 기준으로 제시된 원칙에 맞지 않더라도 이들 문헌 에 한번이라도 제시된 바 있는 국문 과명들은 특별한 이 유가 없는 한 그대로 채택하였으며, 기존에 사용된 국명 이 부적합하다고 생각되는 분류군은 새로운 국명을 제 시하고 그 이유를 밝혔다(Table 1). 기존의 다섯 문헌 간 에 서로 차이가 있는 경우 또한 통일된 기준으로 하나의 이름을 선택하였는데, 합당한 선택 이유가 없는 경우에 는 가장 먼저 국문화된 이름을 따랐다(Table 1).

Table 1. A suggestion of Korean names for the orders and families in the modified APG III classification system (APG, 2009; Stevens, 2015)

\begin{tabular}{|c|c|c|c|c|c|c|}
\hline \multirow[b]{2}{*}{ Taxon ${ }^{*}$} & \multirow[b]{2}{*}{ Suggested Korean Name ${ }^{* \#}$} & \multicolumn{5}{|c|}{ Reference $^{@}$} \\
\hline & & $\begin{array}{c}\text { KPNI } \\
\text { (Korea } \\
\text { National } \\
\text { Arboretum } \\
\text { and The Plant } \\
\text { Taxonomic } \\
\text { Society of } \\
\text { Korea 2007) }\end{array}$ & $\begin{array}{c}\text { GVPK } \\
\text { (Park, 2007) }\end{array}$ & $\begin{array}{l}\text { Kim et al. } \\
\text { (2009) }\end{array}$ & $\begin{array}{c}\text { NLSK } \\
\text { (National } \\
\text { Institute of } \\
\text { Biological } \\
\text { Resources, } \\
\text { 2011) }\end{array}$ & $\begin{array}{l}\text { KPNI-WEB } \\
\text { (Korea } \\
\text { National } \\
\text { Arboretum, } \\
2014 \text { ) }\end{array}$ \\
\hline Amborellales & 암보렐라목 & & & & & \\
\hline Amborellaceae & 암보렐라과 & & & & & \\
\hline Nymphaeales & 수련목 & & & 0 & & 0 \\
\hline Cabombaceae & 어항마름과 & & 0 & 0 & 0 & 0 \\
\hline Hydatellaceae & 하이데 틸라과 & & & & & \\
\hline Nymphaeaceae & 수련과 & 0 & 0 & 0 & 0 & 0 \\
\hline Austrobaileyales & 아스트로베일레아목 (3) & & & 붓순나무목 & & \\
\hline Austrobaileyaceae & 아스트로베일레아과 & & & & & \\
\hline Schisandraceae & 오미자과 & 0 & 0 & 0 & 0 & 0 \\
\hline (+Illiciaceae) & (+붓순나무과) & 0 & ○ & 0 & ○ & O \\
\hline Trimeniaceae & 트라이메니아과 & & & & & \\
\hline Chloranthales & 홀아비꽃대목 & & & ○ & & \\
\hline Chloranthaceae & 홀아비꽃대과 & ○ & $\bigcirc$ & $\bigcirc$ & $\bigcirc$ & ○ \\
\hline MAGNOLIIDS & 목련군 & & & & & \\
\hline Canellales & 카넬라목 & & & & & \\
\hline Canellaceae & 카넬라과 & & & & & \\
\hline Winteraceae & 윈테라과 & & & & & O \\
\hline Piperales & 후추목 & & & O & & O \\
\hline Aristolochiaceae & 쥐방울덩굴과 & 0 & O & O & O & O \\
\hline (+Hydnoraceae) & (+하이드노라과) & & & & & \\
\hline (+Lactoridaceae) & (+락토리스과) & & & & & \\
\hline Piperaceae & 후추과 & $\bigcirc$ & ○ & 0 & ○ & ○ \\
\hline Saururaceae & 삼백초과 & O & O & O & O & O \\
\hline Laurales & 녹나무목 & & & ○ & & O \\
\hline Atherospermataceae & 에쎄로스퍼마과 & & & & & \\
\hline Calycanthaceae & 받침꽃과 & 0 & & & & O \\
\hline Gomortegaceae & 고모테가과 & & & & & \\
\hline Hernandiaceae & 헤르난디아과 & & & & & \\
\hline Lauraceae & 녹나무과 & O & O & O & ○ & ○ \\
\hline Monimiaceae & 모니미아과 2) & & & & & 모니미과 \\
\hline Siparunaceae & 시파루나과 & & & & & \\
\hline Magnoliales & 목련목 & & & O & & O \\
\hline Annonaceae & 뽀뽀나무과 & & & & & O \\
\hline Degeneriaceae & 디제네리아과 & & & & & \\
\hline
\end{tabular}


Table 1. Continued.

\begin{tabular}{|c|c|c|c|c|c|c|}
\hline Eupomatiaceae & 유포메시아과 & & & & & \\
\hline Himantandraceae & 히만텐드라과 & & & & & \\
\hline Magnoliaceae & 목련과 & 0 & $\bigcirc$ & $\bigcirc$ & $\bigcirc$ & O \\
\hline Myristicaceae & 미리스티카과 & & & & & \\
\hline MONOCOTS & 단자엽식물군 & & & & & \\
\hline Acorales & 창포목 & & & 0 & & \\
\hline Acoraceae & 창포과 & & $\mathrm{O}$ & $\mathrm{O}$ & $\bigcirc$ & \\
\hline Alismatales & 택사목 & & & $\bigcirc$ & & $\bigcirc$ \\
\hline Alismataceae & 택사과 & 0 & 0 & $\bigcirc$ & $\bigcirc$ & $\bigcirc$ \\
\hline Aponogetonaceae & 아포노지톤과 & & & & & \\
\hline Araceae & 천남성과 & O & $\bigcirc$ & $\bigcirc$ & $\bigcirc$ & O \\
\hline (+Lemnaceae) & (+개구리밥과) & 0 & 0 & & 0 & $\bigcirc$ \\
\hline Butomaceae & 부토마과 & & & & & $\bigcirc$ \\
\hline Cymodoceaceae & 사이모도시과 & & & & & \\
\hline Hydrocharitaceae & 자라풀과 & $\bigcirc$ & $\bigcirc$ & $\bigcirc$ & $\bigcirc$ & $\bigcirc$ \\
\hline (+Najadaceae) & (+나자스말과) & 0 & $\bigcirc$ & & $\bigcirc$ & O \\
\hline Juncaginaceae & 지채과 & 0 & 0 & $\bigcirc$ & $\bigcirc$ & $\bigcirc$ \\
\hline Posidoniaceae & 포시도니아과 & & & & & \\
\hline Potamogetonaceae & 가래과 & 0 & $\bigcirc$ & $\bigcirc$ & $\bigcirc$ & $\bigcirc$ \\
\hline (+Zannichelliaceae) & (+뿔말과) & & $\bigcirc$ & & $\bigcirc$ & \\
\hline Ruppiaceae & 줄말과 & & $\bigcirc$ & $\bigcirc$ & $\bigcirc$ & \\
\hline Scheuchzeriaceae & 장지채과 & O & 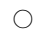 & $\bigcirc$ & 0 & O \\
\hline Tofieldiaceae & 꽃장포과 & & & $\bigcirc$ & & \\
\hline Zosteraceae & 거머리말과 & O & O & O & $\bigcirc$ & O \\
\hline Asparagales & 비짜루목12) & & & $\mathrm{O}$ & & 난초목 \\
\hline Amaryllidaceae & 수선화과 & 0 & $\bigcirc$ & $\bigcirc$ & $\bigcirc$ & O \\
\hline (+Alliaceae) & (+부추과) & & & $\bigcirc$ & & \\
\hline Asparagaceae & 비짜루과 & & & O & & \\
\hline (+Agavaceae) & (+용설란과) & 0 & 0 & $\bigcirc$ & $\bigcirc$ & $\bigcirc$ \\
\hline (+Hyacinthaceae) & $(+ \text { 히야신스수과 })^{3)}$ & & & 비비추과 & & \\
\hline (+Lomandraceae) & (+로만드라과) & & & & & $\bigcirc$ \\
\hline (+Ruscaceae) & $(+ \text { 러스커스과 })^{3)}$ & & & 둥글레과 & & \\
\hline Asphodelaceae & 에스포델러스과 4) & & & & & 트르보란과 \\
\hline (+Hemerocallidaceae) & (+원추리꽃과) & & & O & & \\
\hline (+Phormiaceae) & (+포미움과) & & & & & $\bigcirc$ \\
\hline (+Xanthorrhoeaceae) & (+크산토로에아과) & & & & & O \\
\hline Asteliaceae & 아스텔리아과 & & & & & \\
\hline Blandfordiaceae & 블랜드포디아과 & & & & & \\
\hline Boryaceae & 볼야과 & & & & & \\
\hline Doryanthaceae & 돌얀쎄스과 & & & & & \\
\hline Hypoxidaceae & 노란별수선과 & & & $\mathrm{O}$ & & \\
\hline Iridaceae & 붓꽃과 & O & $\bigcirc$ & $\bigcirc$ & $\bigcirc$ & O \\
\hline Ixioliriaceae & 익시올리리온과 & & & & & \\
\hline Lanariaceae & 라네리아과 & & & & & \\
\hline Orchidaceae & 난초과 & $\bigcirc$ & $\mathrm{O}$ & O & $\bigcirc$ & $\bigcirc$ \\
\hline Tecophilaeaceae & 티코필라에아과 & & & & & \\
\hline Xeronemataceae & 제로니마과 & & & & & \\
\hline Petrosaviales & 페트로세비아목 & & & & & \\
\hline Petrosaviaceae & 페트로세비아과 & & & & & \\
\hline Dioscoreales & 마목 & & & $\bigcirc$ & & \\
\hline Burmanniaceae & 버어먼초과 & 0 & & & & O \\
\hline Dioscoreaceae & 마과 & 0 & 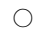 & 0 & $\bigcirc$ & 0 \\
\hline Nartheciaceae & 나르씨시움과3) & & & 쥐꼬리풀과 & & \\
\hline Taccaceae & 타카과 & & & & & $\bigcirc$ \\
\hline Pandanales & 팬디너스목 & & & & & \\
\hline Cyclanthaceae & 시클랜써스과 & & & & & \\
\hline
\end{tabular}




\begin{tabular}{|c|c|c|c|c|c|c|}
\hline Pandanaceae & 팬디너스과 & & & & & 0 \\
\hline Stemonaceae & 스테모나과 & & & & & \\
\hline Triuridaceae & 트라이유리스과 & & & & & \\
\hline Velloziaceae & 벨로지아과 & & & & & \\
\hline Liliales & 백합목 & & & 0 & & 0 \\
\hline Alstroemeriaceae & 알스트로에메리아과 & & & & & 0 \\
\hline Campynemataceae & 캠피네마과 & & & & & \\
\hline Colchicaceae & 콜치움과 ${ }^{3)}$ & & & 애기나리과 & & \\
\hline Corsiaceae & 콜시아과 & & & & & \\
\hline Liliaceae & 백합과 & 0 & 0 & 0 & 0 & 0 \\
\hline Melanthiaceae & 멜란지움과 ${ }^{3)}$ & & & 여로과 & & \\
\hline Petermanniaceae & 피터매니아과 & & & & & \\
\hline Philesiaceae & 필레시아과 & & & & & 0 \\
\hline Rhipogonaceae & 리포고눔과 & & & & & \\
\hline Smilacaceae & 청미래덩굴과 & & $\mathrm{O}$ & 0 & $\bigcirc$ & \\
\hline COMMELINIDS & 닭의장풀아군 & & & & & \\
\hline Arecales & 야자목 & & & & & \\
\hline Arecaceae & 야자과 5) & & & & & 야자나무과 \\
\hline Commelinales & 닭의장풀목 & & & 0 & & $\bigcirc$ \\
\hline Commelinaceae & 닭의장풀과 & 0 & 0 & ○ & 0 & O \\
\hline Haemodoraceae & 지모과 & 0 & & & $\bigcirc$ & O \\
\hline Hanguanaceae & 한구아나과 & & & & & \\
\hline Philydraceae & 필리드럼과 & & & & & \\
\hline Pontederiaceae & 물옥잠과 & 0 & $\mathrm{O}$ & 0 & $\bigcirc$ & 0 \\
\hline Poales & 벼목 & & & 0 & & $\bigcirc$ \\
\hline Anarthriaceae & 에날쓰리아과 & & & & & \\
\hline Bromeliaceae & 파인애플과 & & & & $\bigcirc$ & 0 \\
\hline Cyperaceae & 사초과 & 0 & $\bigcirc$ & $\bigcirc$ & ○ & 0 \\
\hline Ecdeiocoleaceae & 엑디오콜리아과 & & & & & \\
\hline Eriocaulaceae & 곡정초과 & O & O & O & 0 & O \\
\hline Flagellariaceae & 플라젤레리아과 & & & & & \\
\hline Joinvilleaceae & 조인빌리과 & & & & & \\
\hline Juncaceae & 골풀과 & 0 & O & O & O & O \\
\hline Mayacaceae & 메야카과 & & & & & \\
\hline Poaceae & 벼과11) & O & 화본과 & O & 화본과 & ○ \\
\hline Rapateaceae & 라페티아과 & & & & & \\
\hline Restionaceae & 레스티오과 & & & & & O \\
\hline Thurniaceae & 써니아과 & & & & & \\
\hline Typhaceae & 부들과 & 0 & $\bigcirc$ & O & $\bigcirc$ & O \\
\hline (+Sparganiaceae) & (+흑삼릉과) & O & O & O & $\mathrm{O}$ & 0 \\
\hline Xyridaceae & 지리스과 & & & & & \\
\hline Zingiberales & 생강목 & & & O & & 0 \\
\hline Cannaceae & 홍초과 & 0 & O & ○ & O & O \\
\hline Costaceae & 코스터스과 & & & & & \\
\hline Heliconiaceae & 헬리코니아과 & & & & & O \\
\hline Lowiaceae & 로위아과 & & & & & \\
\hline Marantaceae & 마란타과 & & & & & 0 \\
\hline Musaceae & 파초과 & $\bigcirc$ & O & ○ & O & O \\
\hline Strelitziaceae & 스트렐리치아과 & & & & & \\
\hline Zingiberaceae & 생강과 & 0 & 0 & 0 & 0 & 0 \\
\hline SISTER OF EUDICOTS & 진정쌍자엽군의 자매군 & & & & & \\
\hline Ceratophyllales & 붕어마름목 & & & 0 & & \\
\hline Ceratophyllaceae & 붕어마름과 & 0 & 0 & $\bigcirc$ & 0 & 0 \\
\hline$\overline{\text { EUDICOTS }}$ & 진정쌍자엽류 & & & & & \\
\hline Ranunculales & 미나리아재비목 & & & O & & 0 \\
\hline Berberidaceae & 매자나무과 & 0 & 0 & 0 & 0 & 0 \\
\hline
\end{tabular}




\begin{tabular}{|c|c|c|c|c|c|c|}
\hline Circaeasteraceae & 서캐스터과 & & & & & \\
\hline Eupteleaceae & 윱텔레아과 & & & & & $\bigcirc$ \\
\hline Lardizabalaceae & 으름덩굴과 & 0 & 0 & $\bigcirc$ & $\bigcirc$ & O \\
\hline Menispermaceae & 새모래덩굴과 & 0 & 0 & 0 & 0 & 0 \\
\hline Papaveraceae & 양귀비과 & 0 & 0 & O & O & 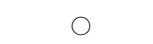 \\
\hline (+Fumariaceae) & (+현호색과) & 0 & 0 & & $\bigcirc$ & $\bigcirc$ \\
\hline Ranunculaceae & 미나리아재비과 & 0 & 0 & 0 & ○ & 0 \\
\hline (+Glaucidiaceae) & (+글라우키디아과) & & & & & $\bigcirc$ \\
\hline Proteales & 프로티아목 12) & & & 연목 & & 0 \\
\hline Nelumbonaceae & 연과 & & $\bigcirc$ & $\bigcirc$ & $\bigcirc$ & \\
\hline Platanaceae & 버즘나무과 & O & 0 & $\bigcirc$ & $\bigcirc$ & $\bigcirc$ \\
\hline Proteaceae & 프로테아과 & & & & & 0 \\
\hline Trochodendrales & 트로코덴드론목 & & & & & \\
\hline Trochodendraceae & 트로코덴드론과 2) & & & & & 트로코덴드라과 \\
\hline Buxales & 회양목목 & & & ○ & & \\
\hline Buxaceae & 회양목과 & 0 & 0 & $\bigcirc$ & $\bigcirc$ & 0 \\
\hline CORE EUDICOTS & 핵심진정쌍자엽류 & & & & & \\
\hline Dilleniales & 덜레니아목 & & & & & $\bigcirc$ \\
\hline Dilleniaceae & 딜레니아과 & & & & & 0 \\
\hline Gunnerales & 거네라목 & & & & & \\
\hline Gunneraceae & 거네라과 & & & & & 0 \\
\hline Myrothamnaceae & 마이로셈너스과 & & & & & \\
\hline Saxifragales & 범의귀목 & & & 0 & & \\
\hline Altingiaceae & 알틴지아과 & & & & & \\
\hline Aphanopetalaceae & 애페노페탈럼과 & & & & & \\
\hline Cercidiphyllaceae & 계수나무과 & $\bigcirc$ & 0 & $\bigcirc$ & $\bigcirc$ & $\bigcirc$ \\
\hline Crassulaceae & 돌나물과 & $\bigcirc$ & O & $\bigcirc$ & $\bigcirc$ & O \\
\hline Cynomoriaceae & 시노모리움과 & & & & & \\
\hline Daphniphyllaceae & 굴거리나무과 & 0 & 0 & 0 & 0 & 0 \\
\hline Grossulariaceae & 까치밥나무과 & & ○ & $\bigcirc$ & $\bigcirc$ & \\
\hline Haloragaceae & 개미탑과 & $\bigcirc$ & $\bigcirc$ & $\bigcirc$ & $\bigcirc$ & $\bigcirc$ \\
\hline Hamamelidaceae & 조록나무과 & $\bigcirc$ & ○ & $\bigcirc$ & $\bigcirc$ & $\bigcirc$ \\
\hline Iteaceae & 이티아과 & & & & & \\
\hline Paeoniaceae & 작약과 & $\bigcirc$ & O & $\bigcirc$ & $\bigcirc$ & O \\
\hline Penthoraceae & 펜쏘럼과 & & & & & \\
\hline Peridiscaceae & 페리디스커스과 & & & & & \\
\hline Saxifragaceae & 범의귀과 & $\bigcirc$ & 0 & $\bigcirc$ & $\bigcirc$ & $\bigcirc$ \\
\hline Tetracarpaeaceae & 테트라카파에아과 & & & & & \\
\hline Vitales & 포도목 & & & & & \\
\hline Vitaceae & 포도과 & 0 & 0 & 0 & 0 & 0 \\
\hline$\overline{\text { ROSIDS }}$ & 장미군 & & & & & \\
\hline EUROSIDS I / FABIDAE & 진정장미군 $\mathrm{I} /$ 콩군 & & & & & \\
\hline Zygophyllales & 남가새목 & & & ○ & & \\
\hline Krameriaceae & 크라메리아과 & & & & & \\
\hline Zygophyllaceae & 남가새과 & 0 & 0 & 0 & $\bigcirc$ & $\bigcirc$ \\
\hline Celastrales & 노박덩굴목 & & & $\bigcirc$ & & O \\
\hline Celastraceae & 노박덩굴과 & 0 & $\bigcirc$ & $\bigcirc$ & 0 & O \\
\hline (+Parnassiaceae) & (+물매화과) & & O & $\bigcirc$ & $\bigcirc$ & \\
\hline Lepidobotryaceae & 레피도보트리스과 & & & & & \\
\hline Oxalidales & 괭이밥목 & & & 0 & & \\
\hline Brunelliaceae & 브루넬리아과 & & & & & \\
\hline Cephalotaceae & 세팔로터스과 & & & & & \\
\hline Connaraceae & 코나루스과 & & & & & \\
\hline Cunoniaceae & 쿠노니아과 & & & & & $\bigcirc$ \\
\hline (+Eucryphiaceae) & (+유크리피아과) & & & & & $\bigcirc$ \\
\hline Elaeocarpaceae & 담팔수과 & 0 & 0 & $\bigcirc$ & $\bigcirc$ & $\bigcirc$ \\
\hline
\end{tabular}




\begin{tabular}{|c|c|c|c|c|c|c|}
\hline Oxalidaceae & 괭이밥과 & 0 & 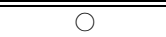 & 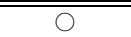 & 0 & 0 \\
\hline Malpighiales & 말피기아목 ${ }^{13)}$ & & & 대극목 & & \\
\hline Achariaceae & 아차리아과 & & & & & \\
\hline Balanopaceae & 벨라놉스과 & & & & & \\
\hline Bonnetiaceae & 보니시아과 & & & & & \\
\hline Calophyllaceae & 켈로필럼과 & & & & & \\
\hline Caryocaraceae & 케리오카과 & & & & & \\
\hline Centroplacaceae & 센트로플래커스과 & & & & & \\
\hline Chrysobalanaceae & 크리소발라너스과 & & & & & \\
\hline Clusiaceae & 클루시아과 ${ }^{6)}$ & 물레나물과 & 물레나물과 & 물레나물과 & 물레나물과 & 물레나물과 \\
\hline Ctenolophonaceae & 티놀로폰과 & & & & & \\
\hline Dichapetalaceae & 디샤페탈럼과 & & & & & \\
\hline Elatinaceae & 물별과 & $\bigcirc$ & O & $\bigcirc$ & O & ○ \\
\hline Erythroxylaceae & 에리쓰록실럼과 & & & & & \\
\hline Euphorbiaceae & 대극과 & 0 & ○ & ○ & O & O \\
\hline Euphroniaceae & 유프로니아과 & & & & & \\
\hline Goupiaceae & 구피아과 & & & & & \\
\hline Humiriaceae & 후미리아과 & & & & & \\
\hline Hypericaceae & 물레나물과1) & & & & & \\
\hline Irvingiaceae & 어빈지아과 & & & & & \\
\hline Ixonanthaceae & 익소낸쎄스과 & & & & & \\
\hline Lacistemataceae & 라시스테마과 & & & & & \\
\hline Linaceae & 아마과 & 0 & O & $\bigcirc$ & O & O \\
\hline Lophopyxidaceae & 로포픽시스과 & & & & & \\
\hline Malpighiaceae & 말피기아과 & & & & & O \\
\hline Ochnaceae & 금연목과 & & & & & O \\
\hline Pandaceae & 팬다과 & & & & & \\
\hline Passifloraceae & 시계꽃과 & 0 & ○ & 0 & O & ○ \\
\hline Phyllanthaceae & 여우주머니과1) & & & & & \\
\hline Picrodendraceae & 피크로덴드론과 & & & & & \\
\hline Podostemaceae & 포도스테뭄과 & & & & & \\
\hline Putranjivaceae & 푸트란지바과 & & & & & \\
\hline Rafflesiaceae & 라플레시아과 & & & & & \\
\hline Rhizophoraceae & 라이조포라과 ${ }^{10)}$ & & & & & 홍수과 \\
\hline Salicaceae & 버드나무과 & 0 & O & O & O & O \\
\hline (+Flacourtiaceae) & (+이나무과) & 0 & (산유자나무과) & & (산유자나무과) & O \\
\hline Trigoniaceae & 트라이고니아과 & & & & & \\
\hline Violaceae & 제비꽃과 & O & O & 0 & O & O \\
\hline Cucurbitales & 박목 & & & 0 & & \\
\hline Anisophylleaceae & 언이소필리과 & & & & & \\
\hline Apodanthaceae & 어포덴쓰과 & & & & & \\
\hline Begoniaceae & 베고니아과 & O & O & O & O & O \\
\hline Coriariaceae & 코리아리아과 & & & & & 0 \\
\hline Corynocarpaceae & 코라이노카푸스과 & & & & & \\
\hline Cucurbitaceae & 박과 & O & 0 & 0 & ○ & O \\
\hline Datiscaceae & 데티스카과 & & & & & \\
\hline Tetramelaceae & 테트라멜레스과 & & & & & \\
\hline Fabales & 콩목 & & & 0 & & O \\
\hline Fabaceae & 콩과 & 0 & O & 0 & O & O \\
\hline Polygalaceae & 원지과 & 0 & O & O & O & 0 \\
\hline Quillajaceae & 퀄라자과 & & & & & \\
\hline Surianaceae & 수리에나과 & & & & & \\
\hline Fagales & 참나무목 & & & 0 & & O \\
\hline Betulaceae & 자작나무과 & 0 & 0 & 0 & O & O \\
\hline Casuarinaceae & 카수아리나과 & & & & & O \\
\hline Fagaceae & 참나무과 & 0 & 0 & 0 & 0 & 0 \\
\hline
\end{tabular}




\begin{tabular}{|c|c|c|c|c|c|c|}
\hline Juglandaceae & 가래나무과 & O & O & $\mathrm{O}$ & $\mathrm{O}$ & O \\
\hline Myricaceae & 소귀나무과 & 0 & 0 & $\bigcirc$ & 0 & $\bigcirc$ \\
\hline Nothofagaceae & 노쏘파거스과 & & & & & \\
\hline Ticodendraceae & 티코덴드론과 & & & & & $\bigcirc$ \\
\hline Rosales & 장미목 & & & $\bigcirc$ & & 0 \\
\hline Barbeyaceae & 바베야과 & & & & & \\
\hline Cannabaceae & 삼과 & 0 & 0 & 0 & O & $\bigcirc$ \\
\hline (+Celtidaceae) & (+팽나무과) & & 0 & & & \\
\hline Dirachmaceae & 디라크마과 & & & & & \\
\hline Elaeagnaceae & 보리수나무과 & 0 & 0 & $\bigcirc$ & 0 & 0 \\
\hline Moraceae & 뽕나무과 & 0 & 0 & $\bigcirc$ & 0 & $\bigcirc$ \\
\hline Rhamnaceae & 갈매나무과 & 0 & 0 & 0 & 0 & 0 \\
\hline Rosaceae & 장미과 & 0 & 0 & $\bigcirc$ & 0 & 0 \\
\hline Ulmaceae & 느릅나무과 & 0 & O & O & O & O \\
\hline Urticaceae & 쐐기풀과 & 0 & $\bigcirc$ & $\bigcirc$ & $\bigcirc$ & $\bigcirc$ \\
\hline EUROSIDS II / MALVIDAE & 진정장미군 II/아욱군 & & & & & \\
\hline Geraniales & 쥐손이풀목 & & & O & & $\bigcirc$ \\
\hline Geraniaceae & 쥐손이풀과 & $\bigcirc$ & 0 & $\bigcirc$ & O & $\bigcirc$ \\
\hline Melianthaceae & 밀리안써스과 & & & & & \\
\hline Vivianiaceae & 비비애니아과 & & & & & \\
\hline Myrtales & 도금양목 & & & & & O \\
\hline Alzateaceae & 알자티아과 & & & & & \\
\hline Combretaceae & 콤브레텀과 2) & & & & & 콤브레타과 \\
\hline Crypteroniaceae & 크립터로니아과 & & & & & \\
\hline Lythraceae & 부처꽃과 & 0 & 0 & $\bigcirc$ & $\bigcirc$ & $\bigcirc$ \\
\hline (+Punicaceae) & (+석류나무과) & 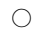 & O & $\bigcirc$ & $\bigcirc$ & $\bigcirc$ \\
\hline (+Trapaceae) & (+마름과) & 0 & O & $\bigcirc$ & O & $\bigcirc$ \\
\hline Melastomataceae & 멜라스토마과 10) & & & & & 야모란과 \\
\hline Myrtaceae & 도금양과 & & & & & O \\
\hline Onagraceae & 바늘꽃과 & $\bigcirc$ & $\bigcirc$ & $\bigcirc$ & $\bigcirc$ & O \\
\hline Penaeaceae & 페나이아과 & & & & & \\
\hline Vochysiaceae & 보치시아과 & & & & & \\
\hline Crossosomatales & 크로소소마타목 ${ }^{13)}$ & & & 고추나무목 & & \\
\hline Aphloiaceae & 아플로이아과 & & & & & \\
\hline Crossosomataceae & 크로소소마타과 & & & & & \\
\hline Geissolomataceae & 가이솔로마과 & & & & & \\
\hline Guamatelaceae & 구아마텔라과 & & & & & \\
\hline Stachyuraceae & 스타치우루스과 & & & & & $\bigcirc$ \\
\hline Staphyleaceae & 고추나무과 & 0 & 0 & $\bigcirc$ & 0 & $\bigcirc$ \\
\hline Strasburgeriaceae & 스트라스버제리아과 & & & & & \\
\hline Picramniales & 피크람니아목 & & & & & \\
\hline Picramniaceae & 피크람니아과 & & & & & \\
\hline Huerteales & 허티아목 & & & & & \\
\hline Dipentodontaceae & 디펜토돈과 & & & & & \\
\hline Gerrardinaceae & 게라르디나과 & & & & & \\
\hline Tapisciaceae & 타피스시아과 & & & & & \\
\hline Brassicales & 십자화목 & & & O & & \\
\hline Akaniaceae & 아카니아과 & & & & & \\
\hline Bataceae & 배티스과 & & & & & \\
\hline Brassicaceae & 십자화과 & 0 & $\bigcirc$ & $\bigcirc$ & 0 & $\bigcirc$ \\
\hline Capparaceae & 카패리스과 & & & & & \\
\hline Caricaceae & 파파야과 & & & & & $\bigcirc$ \\
\hline Cleomaceae & 풍접초과 & 0 & 0 & $\bigcirc$ & 0 & $\bigcirc$ \\
\hline Emblingiaceae & 엠블린지아과 & & & & & \\
\hline Gyrostemonaceae & 자이로스테몬과 & & & & & \\
\hline Koeberliniaceae & 코버리니아과 & & & & & \\
\hline
\end{tabular}




\begin{tabular}{|c|c|c|c|c|c|c|}
\hline Limnanthaceae & 림난체스과 & & & & & \\
\hline Moringaceae & 모린가과 & & & & & \\
\hline Pentadiplandraceae & 펜타딘플란드라과 & & & & & \\
\hline Resedaceae & 레시다과 & & & & & \\
\hline Salvadoraceae & 샐바도라과 & & & & & \\
\hline Setchellanthaceae & 세첼란써스과 & & & & & \\
\hline Tovariaceae & 토배리아과 & & & & & \\
\hline Tropaeolaceae & 한련과 & $\bigcirc$ & 0 & 0 & 0 & $\bigcirc$ \\
\hline Malvales & 아욱목 & & & 0 & & 0 \\
\hline Bixaceae & 빅사과 & & & & & \\
\hline Cistaceae & 시스투스과 & & & & & 0 \\
\hline Cytinaceae & 시티너스과 & & & & & \\
\hline Dipterocarpaceae & 딥테로카푸스과 & & & & & \\
\hline Malvaceae & 아욱과 & 0 & 0 & 0 & 0 & O \\
\hline (+Bombacaceae) & (+물밤나무과) & & & & & $\bigcirc$ \\
\hline (+Sterculiaceae) & (+벽오동과) & 0 & 0 & & 0 & O \\
\hline (+Tiliaceae) & (+피나무과) & O & O & & O & O \\
\hline Muntingiaceae & 문틴지아과 & & & & & \\
\hline Neuradaceae & 니우라다과 & & & & & \\
\hline Sarcolaenaceae & 사콜리나과 & & & & & \\
\hline Sphaerosepalaceae & 스페로세팔럼과 & & & & & \\
\hline Thymelaeaceae & 팥꽃나무과 & 0 & O & O & O & 0 \\
\hline Sapindales & 무환자나무목 & & & O & & 0 \\
\hline Anacardiaceae & 옻나무과 & ○ & 0 & 0 & 0 & O \\
\hline Biebersteiniaceae & 비버스테이니아과 & & & & & \\
\hline Burseraceae & 버세라과 & & & & & \\
\hline Kirkiaceae & 커키아과 & & & & & \\
\hline Meliaceae & 멀구슬나무과 & 0 & 0 & 0 & 0 & O \\
\hline Nitrariaceae & 나이트라리아과 & & & & & \\
\hline Rutaceae & 운향과 & ○ & O & O & 0 & 0 \\
\hline (+Cneoraceae) & (+크네오룸과) & & & & & O \\
\hline Sapindaceae & 무환자나무과 & O & O & O & O & O \\
\hline (+Aceraceae) & (+단풍나무과) & $\bigcirc$ & 0 & & 0 & ○ \\
\hline (+Hippocastanaceae) & (+칠엽수과) & 0 & O & & 0 & ○ \\
\hline Simaroubaceae & 소태나무과 & O & O & O & 0 & O \\
\hline Berberidopsidales & 베버리돕시다목 & & & & & \\
\hline Aextoxicaceae & 액스톡시콘과 & & & & & \\
\hline Berberidopsidaceae & 버베리돕시스과 & & & & & \\
\hline Santalales & 단향목 & & & 0 & & O \\
\hline Balanophoraceae & 밸라노포라과 & & & & & \\
\hline Loranthaceae & 꼬리겨우살이과9) & O & 0 & 0 & 0 & 겨우살이과 \\
\hline Misodendraceae & 미소덴드론과 & & & & & \\
\hline Santalaceae & 단향과 & ○ & O & 0 & O & O \\
\hline Olacaceae & 올락스과 & & & & & \\
\hline Opiliaceae & 오필리아과 & & & & & \\
\hline Schoepfiaceae & 쇼피아과 & & & & & \\
\hline Caryophyllales & 석죽목 & & & 0 & & O \\
\hline Achatocarpaceae & 아카토카푸스과 & & & & & \\
\hline Aizoaceae & 번행초과 & 0 & O & O & 0 & 0 \\
\hline Amaranthaceae & 비름과 & 0 & O & O & 0 & O \\
\hline (+Chenopodiaceae) & (+명아주과) & 0 & 0 & & 0 & 0 \\
\hline Anacampserotaceae & 애나캠세로스과 & & & & & \\
\hline Ancistrocladaceae & 앤시스트로클라더스과 & & & & & \\
\hline Asteropeiaceae & 애스테로피아과 & & & & & \\
\hline Barbeuiaceae & 바부이아과 & & & & & \\
\hline Basellaceae & 바셀라과 & & & & & \\
\hline
\end{tabular}




\begin{tabular}{|c|c|c|c|c|c|c|}
\hline Cactaceae & 선인장과 & 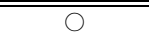 & $\bar{O}$ & $\bar{O}$ & $\mathrm{O}$ & (O \\
\hline Caryophyllaceae & 석죽과 & 0 & 0 & 0 & 0 & 0 \\
\hline (+Illecebraceae) & (+일레케브라과) & & & & & 0 \\
\hline Didiereaceae & 디디에리아과 & & & & & \\
\hline Dioncophyllaceae & 디온코필럼과 & & & & & \\
\hline Droseraceae & 끈끈이귀개과7) & 끈끈이주걱과 & 0 & 0 & 0 & 0 \\
\hline Drosophyllaceae & 드로소필럼과 & & & & & \\
\hline Frankeniaceae & 프란케니아과 & & & & & \\
\hline Gisekiaceae & 기시키아과 & & & & & \\
\hline Halophytaceae & 할로피텀과 & & & & & \\
\hline Limeaceae & 리뭄과 & & & & & \\
\hline Lophiocarpaceae & 로피오카푸스과 & & & & & \\
\hline Molluginaceae & 석류풀과 & 0 & 0 & 0 & 0 & 0 \\
\hline Montiaceae & 몬샤과 & & & & & \\
\hline Nepenthaceae & 벌레잡이풀과 & 0 & & & & 0 \\
\hline Nyctaginaceae & 분꽃과 & 0 & & & O & $\bigcirc$ \\
\hline Physenaceae & 파이세나과 & & & & & \\
\hline Phytolaccaceae & 자리공과 & 0 & 0 & 0 & 0 & 0 \\
\hline Plumbaginaceae & 갯길경이과 ${ }^{8)}$ & 갯질경과 & 갯길경과 & 갯길경과 & 갯길경과 & 갯질경이과 \\
\hline Polygonaceae & 마디풀과 & 0 & O & O & $\bigcirc$ & $\bigcirc$ \\
\hline Portulacaceae & 쇠비름과 & 0 & O & O & O & O \\
\hline Rhabdodendraceae & 랍도덴드론과 & & & & & \\
\hline Sarcobataceae & 사코바터스과 & & & & & \\
\hline Simmondsiaceae & 시몬드시아과 & & & & & \\
\hline Stegnospermataceae & 스테그노스퍼마과 & & & & & \\
\hline Talinaceae & 텔리눔과 & & & & & \\
\hline Tamaricaceae & 위성류과 & 0 & 0 & 0 & & $\bigcirc$ \\
\hline$\overline{\text { ASTERIDS }}$ & 국화군 & & & & & \\
\hline Cornales & 층층나무목 & & & 0 & & 0 \\
\hline Cornaceae & 층층나무과 & 0 & 0 & 0 & 0 & 0 \\
\hline (+Alangiaceae) & (+박쥐나무과) & $\bigcirc$ & O & & 0 & $\bigcirc$ \\
\hline Curtisiaceae & 커티시아과 & & & & & \\
\hline Grubbiaceae & 그루비아과 & & & & & 0 \\
\hline Hydrangeaceae & 수국과 & & 0 & 0 & 0 & \\
\hline Loasaceae & 로사과 & & & & & \\
\hline Ericales & 진달래목 12) & & & 0 & & 철쭉목 \\
\hline Actinidiaceae & 다래나무과 & 0 & 0 & 0 & 0 & 0 \\
\hline Balsaminaceae & 봉선화과 & 0 & O & O & 0 & $\bigcirc$ \\
\hline Clethraceae & 매화오리나무과 ${ }^{7)}$ & ○ & 매화오리과 & 매화오리과 & 매화오리과 & $\bigcirc$ \\
\hline Cyrillaceae & 사이릴라과 & & & & & \\
\hline Diapensiaceae & 암매과 & 0 & 0 & 0 & 0 & 0 \\
\hline Ebenaceae & 감나무과 & 0 & O & O & 0 & 0 \\
\hline Ericaceae & 진달래과 & 0 & O & O & 0 & 0 \\
\hline (+Empetraceae) & (+시로미과) & 0 & 0 & & 0 & 0 \\
\hline (+Monotropaceae) & (+수정난풀과) & & 0 & & $\bigcirc$ & \\
\hline (+Pyrolaceae) & (+노루발과) & $\bigcirc$ & $\bigcirc$ & & & $\bigcirc$ \\
\hline Fouquieriaceae & 푸퀴어리아과 & & & & & \\
\hline Lecythidaceae & 레시씨스과 & & & & & \\
\hline Marcgraviaceae & 마크그라비아과 & & & & & \\
\hline Mitrastemonaceae & 미트라스테마과 & & & & & \\
\hline Pentaphylacaceae & 펜타필락스과 & & & & & \\
\hline Polemoniaceae & 꽃고비과 & 0 & 0 & 0 & 0 & 0 \\
\hline Primulaceae & 앵초과 & 0 & 0 & 0 & O & O \\
\hline (+Maesaceae) & (+빌레나무과) & & & & $\bigcirc$ & O \\
\hline (+Myrsinaceae) & (+자금우과) & ○ & O & O & 0 & $\bigcirc$ \\
\hline Roridulaceae & 로리듈라과 & & & & & \\
\hline
\end{tabular}




\begin{tabular}{|c|c|c|c|c|c|c|}
\hline $\begin{array}{l}\text { Sapotaceae } \\
\end{array}$ & 사포테과 & & & & & O \\
\hline Sarraceniaceae & 사라시니아과 & & & & & 0 \\
\hline Sladeniaceae & 슬라데니아과 & & & & & \\
\hline Styracaceae & 때죽나무과 & 0 & 0 & 0 & 0 & 0 \\
\hline Symplocaceae & 노린재나무과 & 0 & O & 0 & 0 & O \\
\hline Tetrameristaceae & 테트라메리스타과 & & & & & \\
\hline Theaceae & 차나무과 & $\bigcirc$ & 0 & 0 & 0 & 0 \\
\hline EUASTERID I / LAMIIDS & 진정국화군 I / 꿀풀군 & & & & & \\
\hline Boraginales & 지치목 & & & 0 & & \\
\hline Boraginaceae & 지치과 & 0 & ○ & 0 & ○ & 0 \\
\hline Hydrophyllaceae & 히드로필럼과 & & & & & 0 \\
\hline Garryales & 식나무목 & & & 0 & & \\
\hline Eucommiaceae & 두충과 & 0 & 0 & 0 & 0 & 0 \\
\hline Garryaceae & 가리아과6) & & & 식나무과 & & 0 \\
\hline (+Aucubaceae) & (+식나무과) & & 0 & & 0 & \\
\hline Gentianales & 용담목 & & & 0 & & 0 \\
\hline Apocynaceae & 협죽도과 & 0 & 0 & 0 & 0 & 0 \\
\hline (+Asclepiadaceae) & (+박주가리과) & ○ & O & & 0 & O \\
\hline Gelsemiaceae & 겔세미엄과 & & & & & \\
\hline Gentianaceae & 용담과 & 0 & 0 & 0 & 0 & 0 \\
\hline Loganiaceae & 마전과 & 0 & 0 & 0 & 0 & 0 \\
\hline Rubiaceae & 꼭두선이과7) & 꼭두서니과 & O & 0 & O & 꼭두서니과 \\
\hline Lamiales & 꿀풀목 & & & O & & ○ \\
\hline Acanthaceae & 쥐꼬리망초과 & 0 & ○ & 0 & O & $\bigcirc$ \\
\hline Bignoniaceae & 능소화과 & ○ & 0 & 0 & 0 & 0 \\
\hline Byblidaceae & 비블리스과 & & & & & O \\
\hline Calceolariaceae & 칼시올라리아과 & & & & & \\
\hline Carlemanniaceae & 칼매니아과 & & & & & \\
\hline Gesneriaceae & 제스네리아과 7) & 게스네리아과 & & & O & O \\
\hline Lamiaceae & 꿀풀과 & 0 & 0 & 0 & 0 & 0 \\
\hline Linderniaceae & 밭둑외풀과1) & & & & & \\
\hline Lentibulariaceae & 통발과 & 0 & ○ & 0 & ○ & O \\
\hline Martyniaceae & 마티니아과 & & & & & \\
\hline Oleaceae & 물푸레나무과 & 0 & 0 & 0 & 0 & 0 \\
\hline Orobanchaceae & 열당과 & ○ & ○ & $\bigcirc$ & O & $\bigcirc$ \\
\hline Paulowniaceae & 오동나무과 ${ }^{1)}$ & & & & & \\
\hline Pedaliaceae & 참깨과 & 0 & 0 & 0 & 0 & 0 \\
\hline Phrymaceae & 파리풀과 & 0 & 0 & 0 & 0 & 0 \\
\hline Plantaginaceae & 질경이과 & ○ & $\bigcirc$ & $\bigcirc$ & ○ & $\bigcirc$ \\
\hline (+Callitrichaceae) & (+별이끼과) & ○ & ○ & & ○ & $\bigcirc$ \\
\hline (+Globulariaceae) & (+글로불라리아과) & & & & & O \\
\hline (+Hippuridaceae) & (+쇠뜨기말풀과) & 0 & & & & 0 \\
\hline Plocospermataceae & 플로코스퍼마과 & & & & & \\
\hline Schlegeliaceae & 슐르길리아과 & & & & & \\
\hline Scrophulariaceae & 현삼과 & ○ & ○ & ○ & ○ & O \\
\hline (+Myoporaceae) & (+미오포라과) & & & & & 0 \\
\hline Stilbaceae & 스틸브과 & & & & & \\
\hline Tetrachondraceae & 테트라콘드라과 & & & & & \\
\hline Thomandersiaceae & 쏘만더시아과 & & & & & \\
\hline Verbenaceae & 마편초과 & O & 0 & O & 0 & O \\
\hline Solanales & 가지목 & & & 0 & & 0 \\
\hline Convolvulaceae & 메꽃과 & ○ & O & O & O & $\bigcirc$ \\
\hline Hydroleaceae & 하이드롤리아과 & & & & & \\
\hline Montiniaceae & 몬티니아과 & & & & & \\
\hline Solanaceae & 가지과 & 0 & 0 & 0 & 0 & 0 \\
\hline Sphenocleaceae & 스페노클리과 & & & & & \\
\hline $\begin{array}{l}\text { TAXA OF UNCERTAIN } \\
\text { POSITION IN EUASTERID I }\end{array}$ & $\begin{array}{l}\text { 진정국화군 I 에서 위치가 } \\
\text { 불명확한 분류군들 }\end{array}$ & & & & & \\
\hline
\end{tabular}


Table 1. Continued.

\begin{tabular}{|c|c|c|c|c|c|c|}
\hline Icacinales & 아이카시나목 & & & & & \\
\hline Icacinaceae & 아이카시나과 & & & & & \\
\hline Oncothecaceae & 온코씨카과 & & & & & \\
\hline Metteniusales & 메테니우사목 & & & & & \\
\hline Metteniusaceae & 메테니우사과 & & & & & \\
\hline \multicolumn{7}{|c|}{ EUASTERID II / CAMPANULIDS 진정국화군 II / 초롱꽃군 } \\
\hline Apiales & 산형목 & & & 미나리목 & & 미나리목 \\
\hline Apiaceae & 산형과 ${ }^{11)}$ & $\bigcirc$ & 미나리과 & O & 미나리과 & $\bigcirc$ \\
\hline Araliaceae & 두릅나무과 & $\bigcirc$ & $\bigcirc$ & O & $\bigcirc$ & $\bigcirc$ \\
\hline Griseliniaceae & 그리셀리니아과 & & & & & $\bigcirc$ \\
\hline Myodocarpaceae & 미오도카푸스과 & & & & & \\
\hline Pennantiaceae & 페난샤과 & & & & & \\
\hline Pittosporaceae & 돈나무과 & 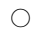 & $\bigcirc$ & O & $\bigcirc$ & $\bigcirc$ \\
\hline Torricelliaceae & 토리첼리아과 & & & & & \\
\hline Aquifoliales & 감탕나무목 & & & 0 & & \\
\hline Aquifoliaceae & 감탕나무과 & 0 & $\bigcirc$ & 0 & 0 & $\bigcirc$ \\
\hline Cardiopteridaceae & 카디옵터리스과 & & & & & \\
\hline Helwingiaceae & 헬윙기아과 & & & & & $\bigcirc$ \\
\hline Phyllonomaceae & 필로노마과 & & & & & \\
\hline Stemonuraceae & 스테모누러스과 & & & & & \\
\hline Asterales & 국화목 & & & 0 & & O \\
\hline Alseuosmiaceae & 알슈오스미아과 & & & & & \\
\hline Argophyllaceae & 아고필럼과 & & & & & \\
\hline Asteraceae & 국화과 & 0 & 0 & 0 & 0 & $\bigcirc$ \\
\hline Calyceraceae & 켈리시라과 & & & & & \\
\hline Campanulaceae & 초롱꽃과 & 0 & $\bigcirc$ & O & O & O \\
\hline Goodeniaceae & 구데니아과 & & & & & $\bigcirc$ \\
\hline Menyanthaceae & 조름나물과 & $\bigcirc$ & O & 0 & $\bigcirc$ & $\bigcirc$ \\
\hline Pentaphragmataceae & 펜타프라그마과 & & & & & \\
\hline Phellinaceae & 펠린과 & & & & & \\
\hline Rousseaceae & 로우시과 & & & & & \\
\hline Stylidiaceae & 스타일리둠과 & & & & & \\
\hline Escalloniales & 에스칼로니아목 & & & & & \\
\hline Escalloniaceae & 에스칼로니아과 & & & & & $\bigcirc$ \\
\hline Bruniales & 부르니아목 & & & & & \\
\hline Bruniaceae & 부르니아과 & & & & & \\
\hline Columelliaceae & 콜루멜리아과 & & & & & \\
\hline Paracryphiales & 패라크리피아목 & & & & & \\
\hline Paracryphiaceae & 패라크리피아과 & & & & & \\
\hline Dipsacales & 산토끼꽃목13) & & & & & 산토끼목 \\
\hline Adoxaceae & 연복초과 & O & $\bigcirc$ & O & O & O \\
\hline (+Viburnaceae) & (+산분꽃나무과) & & 0 & & O & \\
\hline Caprifoliaceae & 인동과 & $\mathrm{O}$ & O & O & O & $\bigcirc$ \\
\hline (+Diervillaceae) & (+병꽃나무과) & & $\bigcirc$ & $\bigcirc$ & O & \\
\hline (+Dipsacaceae) & (+산토끼꽃과) & $\bigcirc$ & O & O & O & $\bigcirc$ \\
\hline (+Linnaeaceae) & (+린네풀과) & & $\bigcirc$ & O & O & \\
\hline (+Valerianaceae) & (+마타리과) & $\bigcirc$ & $\bigcirc$ & $\bigcirc$ & 0 & $\bigcirc$ \\
\hline $\begin{array}{l}\text { TAXA OF UNCERTAIN } \\
\text { POSITION IN ANGIOSPERMS }\end{array}$ & $\begin{array}{l}\text { 피자식물 중 위치가 } \\
\text { 불명확한 분류군들 }\end{array}$ & & & & & \\
\hline Dasypogonaceae & 데시포곤과 & & & & & \\
\hline Huaceae & 후아과 & & & & & \\
\hline Hydrostachyaceae & 하이드로스타치스과 & & & & & \\
\hline Sabiaceae & 나도밤나무과 & $\bigcirc$ & $\bigcirc$ & O & O & O \\
\hline Vahliaceae & 바흘리아과 & & & & & \\
\hline
\end{tabular}

*, names in the parenthesis are combined with other families in the APG III and APW.

\#, newly suggested order and family names in this study are indicated as bold characters; superscript numbers are matched with case numbers indicated in the text.

@, circles indicate same Korean names with those accepted in this study; Korean characters in reference columns indicate alternative Korean names in the previous references. 
과명의 국문화는 지금까지 box 1 에서 제시된 여러 가지 방법으로 이루어져 왔다. APG III분류체계 상에서 위의 다 섯 문헌에 포함되지 않은 과들에 대한 국문화는 2-1, 2-2, 2-3의 방법 중 한가지를 택하여 명명할 수 있는데, 본 연구 에서는 2-3의 방법인 기준속을 영어 식 발음대로 표기하 고 뒤에 “과”를 붙이는 방법이 타당하다고 판단되어 이를 따랐고, 2-1과 2-2 방법에 대한 문제점은 결과 및 고찰에서 논의 하였다. 기준속의 발음법은 영어 발음과 라틴어 발음 을 선택할 수 있는데, 본 연구에서는 Mac OS X (Yosemite; ver. 10.10.2) 에서 제공하는 영어발음에 의거한 국립국어원 에서 제공하는 외래어 표기법 규정(http://www.korean.go.kr/ front/page/pageView.do?page_id=P000104\&mn_id=97)에 따른 속명의 영어 발음에 의거하여 국문화 하였다.

목명의 국문화 또한 과명의 국문화 방법과 동일한 기준 을 적용하였다. 국문 목명에 대해서는 KPNI, GVPK, 및 NLSK에서는 다룬 바 없어, Kim et al. (2008)과 및 KPNIWEB (Korea National Arboretum, 2014)에서 제시한 국문들 만을 비교 검토하였다. 이들 두 문헌에서 다룬 바 없는 목명 들은 과의 국문화 방법과 동일한 방법으로 국문화 하였다.

\section{결과 및 고찰}

위에서 제시된 기준에 의해 APW (ver. 14; Stevens, 2015) 를 반영한 APG III (APG, 2009) 분류체계에 해당되는 63목 411과에 대한 국명을 제시하였다(Table 1). 기존의 다섯 문 헌에서 상이점 없이 사용된 이름들은 180 과에 해당하며, 서로 다른 국명이 제시된 바 있는 8 개 과에 대해서는 이들 을 검토하여 하나의 이름을 선정하였다(아래 각각의 분류 군에 대한 검토 참조). 기존에 국문화 된 적 없는 22 목 223 과에 대해서는 새로 국명을 제시하였다. 기존의 다섯 문헌 에 포함된바 있는 국문 과명들 중 APW (ver. 14; Stevens, 2015)에서 다른 과에 합쳐져 현재 분류체계에서 사용되지 않는 48 개 과들도 향후 과의 한계 변화 가능성을 고려하여 같은 방법으로 국문화 하였다(Table 1 , 괄호로 표시). 국명 을 선정 및 재검토 한 경우에 선정 이유와 이에 대한 고찰 을 아래에서 각각 설명하였으며, 이에 해당하는 번호를 Table 1의 해당 분류군에 위 첨자로 표시하였다.

1) APG III (APG, 2009) 분류체계에서 기존의 분류체 계상의 속이 과로 승격되어 새 국명이 필요한데, 기준속 이 우리나라에 존재하는 경우는 Hyperaceae (물레나물 과), Phyllanthaceae (여우주머니과), Linderniaceae (밭둑외풀 과), Paulowniaceae (오동나무과)이며, 이들은 기준속에 의 거하여 과명을 국문화 하였다(Table 1 superscript 1).

2) 기존의 문헌에서 이미 2-3의 방법에 의해 소리나는 대로 국문화 되어있는 경우에 몇몇은 속의 어미를 따르지 않아 발생한 오류가 있다. 예를 들어 Monimiaceae를 "모니 미과”로 국문화한 경우가 있지만(Korea National Arboretum, 2014), 이의 기준속은 Monimia로서 “모니미아
과"가 타당하다. 같은 예로 KPNI-WEB (Korea National Arboretum, 2014)에 있어서 Trochodendraceae를 “트로코덴 드라과”로, Combretaceae를 “콤브레타과”로 국문화된 바 있지만 본 연구에서는 각각 “트로코덴드론과”와 “콤브레 텀과”로 수정하였다(Table 1 superscript 2; Table 2).

3) Colchicaceae, Hyacinthaceae, Melanthiaceae, Nartheciaceae, Ruscaceae는 APG system에서 새롭게 인식된 과들인데, 각각 우리나라에 기준속이 존재하지 않아 우리나라에 존재하는 Disporum (애기나리속), Hosta (비비추속), Veratrum (여로속), Aletris (쥐꼬리풀속), Polygonatum (둥글레속)을 기준으로 국문 과명을 제시한 바 있다(Kim et al., 2008). 그러나 본 연구에서는 새롭게 명명되는 국명에 안정성을 높이고자 기준 속들에 의 거하여 신칭하였다(Table 1 superscript 3; Table 2; 아래 6) 참조).

4) Asphodelaceae는 KPNI-WEB (Korea National Arboretum, 2014)에 있어서 “트로보란과”로 표기되어 있 지만 그 기원을 파악할 수 없어 “에스포델러스과”로 신칭 하였다(Table 1 superscript 4; Table 2).

5) Arecaceae는 단자엽식물이므로 2차 목부에 해당하는 “나무”라는 이름을 붙이는 것이 타당하지 않다. 그러므로 “야자나무과”가 아닌 “야자과”를 채택하였다(Table 1 superscript 5; Table 2).

6) Clusiaceae는 기준 속인 Clusia가 우리나라에 분포하지 않아 box 1의 2-1 방법에 따라 국문화되어 우리나라에 존재 하는 속인 물레나물속(Hypericum)에 의거하여 “물레나물 과”로 불려왔다(Korea National Arboretum and The Plant Taxonomic Society of Korea, 2007; Park, 2007; Kim et al., 2008; National Institute of Biological Resources, 2011; Korea National Arboretum, 2014). 그러나 APG 분류체계에서는 Hyperiaceae 를 Clusiaceae 에서 분리하여 독립된 과로 인정함에 따라 본 연구에서는 Hyperiaceae의 국명을 물레나물과로 사용하고 기존에 물레나물과로 불려온 Clusiaceae를 “클루시아과”로 새로 명명하였다(Table 1 superscript 6; Table 2). 비슷한 예로 Aucubaceae에 대하여 GVPK (Park, 2007)와 NLSK (National Institute of Biological Resources, 2011)은 Acuba (식나무속)에 의거하여 “식나무과”로 표기하였지만, APG II (2003)에 따 른 Kim et al. (2008)에서는 Aucubaceae가 Garryaceae에 포함되 어 box 1의 2-1의 방법에 따라 Garryaceae를 식나무과로 표기 한 바 있다. 그러나 이 또한 기준속에 근거하지 않은 국명은 안정성을 제공하지 못하여 2-3의 방법에 의해 KPNI-WEB (Korea National Arboretum, 2014)에서 표기된 바 있는 “가리아 과"가 타당하다(Table 1 superscript 6; Table 3). 위의 두가지 예 는 2-1에 의한 국문화 방법의 문제점을 잘 보여주고 있어 이 는 본 연구에서 2-3 방법에 의한 국문화 방법을 채택한 이유 가 되고 있다.

7) 기존의 다섯 문헌에서 국문 과명이 서로 약간 다른 경우 가 있는데, Rubiaceae는 “꼭두서니과” 또는 “꼭두선이과”로, Clethraceae는 "매화오리나무과” 또는 “매화오리과”로, Flacourtiaceae는 “이나무과” 또는 “산유자나무과로”, Droseraceae 
는 “끈끈이귀개과” 또는 "끈끈이주걱과”로 제시된 바 있다. 이 경우에는 어떤 것을 사용하여도 무방하지만, 우리나라에 서 가장 먼저 식물 국문명에 대한 종합이 이루어진 조선식물 향명집(Chung et al., 1937)에서 각각 “꼭두선이과”와 “매화오리 나무과”로 언급되어 있어 본 연구에서는 이를 채택하였다.

Flacourtiaceae는 KPNI (Korea National Arboretum and The Plant Taxonomic Society of Korea, 2007)와 GVPK (Park, 2007)에서 가장 먼저 국문화 되었는데, 두 문헌이 같은 연도에 발간되어 본 연 구에서는 “이나무과”를 임의적으로 선택하였다. Droseraceae 는 Chung et al. (1937)에서 “근근이과”로 사용되었는데, 현재 사 용하는 과명과는 차이가 있어 위의 다섯 문헌에서 제시된 과 명 중 임의로 “끈근이귀개과”로 선택하였다. Gesneriaceae는 “ 제스네리아과” 또는 "게스네리아과”로 사용되었는데, 라틴 어식 발음인 “게스네리아" 보다 영어식 발음인 “제스네리아 과”를 채택하였다(Table 1, superscript 7; Table 3).

8) Plumbaginaceae의 경우 "갯길경과(Park, 2007; Kim et al., 2008; National Institute of Biological Resources, 2011)", "갯질경과(Korea National Arboretum and The Plant Taxonomic Society of Korea, 2007)", “갯질경이과(Korea National Arboretum, 2014)"로 매우 혼란되게 사용되어 왔 는데, 이는 국명의 기준이 된 종인 "갯길경이[Statice japonica Siebol \& Zucc.=Limonium tetragonum (Thunb.) Bullock]"가 Chung et al. (1937)에서 가장 먼저 언급된 이래 비슷한 이름의 "갯질경이[Plantago major for. yezomaritima (Koidz.) Ohwi; Plantaginaceae (질경이과)]"와 혼동되어 사 용된 오류로 판단된다. 그러므로 “갯질경과” 또는 "갯질경 이과”의 사용은 타당하지 않다. 한편 Chung et al. (1937)에서 는 갯길경이가 속한 과를 "기송(僟松)과”로 가장 먼저 언급 하였는데, 이는 현재 일반적으로 널리 사용되는 이름은 아 니라고 판단된다. 갯길경이는 본 과의 기준속이 아니므로 box 1 의 2-3의 방법에 의해 “플럼바고과”로 사용하는 것이 논리적으로는 가장 타당하다. 하지만 지금까지 국가기관 에 의해 발표되어 널리 사용되어온 다섯 문헌(Korea National Arboretum and The Plant Taxonomic Society of Korea, 2007; Park, 2007; Kim et al., 2008; National Institute of Biological Resources, 2011; Korea National Arboretum, 2014)에서 철자는 다르지만 일관된 의미로 사용되어온 것을 고려하여, 본 연 구에서는 철자를 수정하여 "갯길경이과" 사용하는 것이 타 당하다고 판단하였다(Table 1, superscript 8; Table 3).

9) Loranthaceae의 기준속은 Loranthus (꼬리겨우살이속) 로, 기존에 발표된 국문 과명 중 기준속의 국명과에 일치하 는 국문 과명을 선택하였다(Table 1, superscript 9; Table 3).

Table 2. Korean names (order or family) changed in this study from previously suggested names

\begin{tabular}{|c|c|c|c|c|}
\hline Order or Family & Previous Korean name & $\begin{array}{l}\text { Previous } \\
\text { reference }\end{array}$ & Type genus & New Korean name \\
\hline Austrobaileyales & 붓순나무목 & $\mathrm{c}$ & Austrobaileya & 아스트로베일레아목 \\
\hline Crossosomatales & 고추나무목 & $\mathrm{c}$ & Crossosomata & 크로소소마타목 \\
\hline Dipsacales & 산토끼목 & $\mathrm{e}$ & Dipsacus & 산토끼꽃목 \\
\hline Malpighiales & 대극목 & $\mathrm{c}$ & Malpighia & 말피기아목 \\
\hline Arecaceae & 야자나무과 & $\mathrm{e}$ & Areca & 야자과 \\
\hline Asphodelaceae & 트르보란과 & $\mathrm{e}$ & Asphodelus & 에스포델러스과 \\
\hline Clusiaceae & 물레나물과 & $\mathrm{a}, \mathrm{b}, \mathrm{c}, \mathrm{d}, \mathrm{e}$ & Clusia & 클루시아과 \\
\hline Colchicaceae & 애기나리과 & $\mathrm{c}$ & Colchium & 콜치움과 \\
\hline Combretaceae & 콤브레타과 & $\mathrm{e}$ & Combretum & 콤브레텀과 \\
\hline Hyacinthaceae & 비비추과 & $\mathrm{c}$ & Hyacinthus & 히야신수스과 \\
\hline Melastomataceae & 홍수과 & $\mathrm{e}$ & Melastomata & 멜라스토마과 \\
\hline Melanthiaceae & 여로과 & $\mathrm{c}$ & Melanthium & 멜란지움과 \\
\hline Monimiaceae & 모니미과 & $\mathrm{e}$ & Monimia & 모니미아과 \\
\hline Nartheciaceae & 쥐꼬리풀과 & $\mathrm{c}$ & Narthecium & 나르씨시움과 \\
\hline Rhizophoraceae & 야모란과 & $\mathrm{e}$ & Rhizophora & 라이조포라과 \\
\hline Ruscaceae & 둥글레과 & $\mathrm{c}$ & Ruscus & 러스커스과 \\
\hline Trochodendraceae & 트로코덴드라과 & $\mathrm{e}$ & Trochodendron & 트로코덴드론과 \\
\hline
\end{tabular}

a, KPNI (Korea National Arboretum and The Plant Taxonomic Society of Korea ,2007)

b, GVPK (Park, 2007)

c, Kim et al. (2009)

d, NLSK (National Institute of Biological Resources, 2011)

e, KPNI-WEB (Korea National Arboretum, 2014) 
10) Melastomataceae와 Rhizophoraceae는 box 1의 2-2에 서 제시한 바와 같이 우리나라에 분포하지 않는 식물들로 KPNI-WEB (Korea National Arboretum, 2014)에서는 재배 식물의 명명을 위해 중국식물지로부터 한자명을 도입하 여 각각 “야모란과”와 “홍수과”로 표기한 바 있다. 국내에 존재하지 않는 과에 대하여 한자권 국가에서 쓰는 이름의 직역은 이들이 우리나라 사람이 전혀 알지 못하는 식물이 므로 국문 과명으로써 바람직하지 못하다. 이에 2-3의 방 법에 의해 이들을 각각 "멜라스토마과”와 "라이조포라과" 로 다시 국문화하였다(Table 1, superscript 10; Table 2).

11) Apiaceae (Umbelliferae)와 Poaceae (Graminae)는 국제조 류균류식물명명규약(International Code of Algae, Fungi, and Plants; ICN)에 의거하여 두 개의 공식적 이름을 갖는 과들이 다. Apiaceae의 경우 이 식물군이 갖는 대표적 형질인 산형화 서(umbel)에 따른 Umbelliferae라는 이름이 오랫동안 사용되 어 온 것이고, 이러한 이유로 우리나라에서도 “산형과”라는 국명이 사용되어 왔다. GVPK (Park, 2007)과 NLSK (National Institute of Biological Resources, 2011)에서는 Apiaceae를 미나 리과”로 표기하였는데, 이는 이 과에 속하는 대표적 우리나 라 식물인 미나리로부터 차용된 이름이다. 그러나 미나리 는 Apiaceae의 기준속에 속하지 않기 때문에 “산형과"를 사 용하였다. Poaceae의 경우 “벼과”(Korea National Arboretum and The Plant Taxonomic Society of Korea, 2007; Kim et al., 2008; Korea National Arboretum, 2014)와 “화본과” (Park, 2007;
National Institute of Biological Resources, 2011)가 혼용되어 사 용되어 왔는데, 두 이름 모두 기준속을 근거로 한 이름은 아 니지만 친숙하지 않은 한자어인 “화본과” 보다 단일식물명 을 도입한 과명인 “벼과”를 사용하는 것이 더 타당하다고 판단하였다(Table 1, superscript 11; Table 2).

목은 기준 과를 바탕으로 이름 지어진 것이고, 과는 기준 속을 바탕으로 이름 지어진 것이므로 목을 국문화 할 때 목 의 기준과의 이름을 제공한 기준속의 발음에 “목”을 붙여 국문화하는 것이 타당하다. 예를 들어 Pandanales의 기준과 는 Pandanaceae이고 이 과의 기준속은 Pandanus로써 “팬디 나목"이 아닌 “팬디너스목”으로 사용하였다(Table 1).

12) 우리나라 분류군들이 속한 목들의 국문이 Kim et al. (2008)과 KPNI-WEB (Korea National Arboretum, 2014)이 서로 다른 경우는 Asparagales, Proteales, Ericales인데, 기준속인 Asparagus (비짜루속), Protea (프로티아속), Erica (진달래속) 에 의해 제시된 바 있는 목명인 “비짜루목", “프로티아목", "진달래목"을 채택하였다(Table 1, superscript 12; Table 3).

13) Kim et al. (2008) 또는 KPNI-WEB (Korea National Arboretum, 2014)에서 단 한번만 제시되었지만 본 연구에서 수정된 목들은 Austrobaileyales, Malpighiales, Crossosomatales, Dipsacales 이다. Austrobaileyales의 경우 Kim et al. (2008)에서 국내에 분포하는 속인 Illicium (붓순나무속)에 의해 “붓순나 무목"으로 사용된 바 있지만, 본 연구에서는 기준속인

Table 3. Alternative Korean names (order and family) suggested in previous references and accepted Korean names in this study

\begin{tabular}{|c|c|c|c|c|c|c|}
\hline Order or Family & $\begin{array}{c}\text { Selected Korean } \\
\text { family name in this } \\
\text { study }\end{array}$ & $\begin{array}{c}\text { KPNI } \\
\text { (Korea National } \\
\text { Arboretum and The } \\
\text { Plant Taxonomic } \\
\text { Society of Korea, } \\
\text { 2007) }\end{array}$ & $\begin{array}{c}\text { GVPK } \\
\text { (Park, 2007) }\end{array}$ & Kim et al. (2008) & $\begin{array}{c}\text { NLSK } \\
\text { (National Institute } \\
\text { of Biological } \\
\text { Resources, 2011) }\end{array}$ & $\begin{array}{l}\text { KPNI-WEB } \\
\text { (Korea National } \\
\text { Arboretum, 2014) }\end{array}$ \\
\hline Asparagales & 비짜루목 & - & - & 비짜루목 & - & 난초목 \\
\hline Apiales & 산형목 & - & - & 미나리목 & - & - \\
\hline Ericales & 진달래목 & - & - & 진달래목 & - & 철쭉목 \\
\hline Proteales & 프로티아목 & - & - & 연목 & - & 프로티아목 \\
\hline Apiaceae & 산형과 & 산형과 & 미나리과 & 산형과 & 미나리과 & 산형과 \\
\hline Clethraceae & 매화오리나무과 & 매화오리나무과 & 매화오리과 & 매화오리과 & 매화오리과 & 매화오리과 \\
\hline Droseraceae & 끈끈이귀개과 & 끈근이주걱과 & 끈끈이귀개과 & 끈근이귀개과 & 끈끈이귀개과 & 끈끈이귀개과 \\
\hline Flacourtiaceae & 이나무과 & 이나무과 & 산유자나무과 & - & 산유자나무과 & 이나무과 \\
\hline Garryaceae & 가리아과 & - & $\begin{array}{l}\text { 식나무과 } \\
\text { (Aucubaceae) }\end{array}$ & 식나무과 & $\begin{array}{l}\text { 식나무과 } \\
\text { (Aucubaceae) }\end{array}$ & 가리아과 \\
\hline Gesneriaceae & 제스네리아과 & 게스네리아과 & - & - & 제스네리아과 & 제스네리아과 \\
\hline Loranthaceae & 꼬리겨우살이과 & 꼬리겨우살이과 & 꼬리겨우살이과 & 꼬리겨우살이과 & 꼬리겨우살이과 & 겨우살이과 \\
\hline Plumbaginaceae & 갯길경이과 & 갯질경이과 & 갯길경과 & 갯길경과 & 갯길경과 & 갯질경이과 \\
\hline Poaceae & 벼과 & 벼과 & 화본과 & 벼과 & 화본과 & 벼과 \\
\hline Rubiaceae & 꼭두선이과 & 꼭두서니과 & 꼭두선이과 & 꼭두선이과 & 꼭두선이과 & 꼭두서니과 \\
\hline
\end{tabular}


Austrobaileya에 의해 “아스트로베일레아목"으로 국문화하 였다. 만약 Austrobaileyales를 “붓순나무목”으로 사용한다면 향후 Illiciales가 인정되어 사용할 경우 매우 큰 혼란을 야기 할 수 있다. 또한 Cronquist system (Cronquist, 1981)에서는 Illiciales를 인정한 바 있다. Malpighiales와 Crossosomatales는 Kim et al. (2008)에서 각각 “대극목"과 “고추나무목”으로 사 용되었지만, Austrobaileyales와 같은 이유로 기준속에 의한 이름인 “말피기아목”과 “크로소소마타목”으로 신칭하였 다. Dipsacales의 경우 KPNI-WEB (Korea National Arboretum, 2014)에서는 “산토끼목"으로 사용하고 있는데, 이는
Dipsacus (산토끼꽃속)을 기준으로한 “산토끼꽃목”의 오기 로 판단되어 수정하였다(Table 1, superscript 13; Table 2).

Kim et al. (2008)에서는 Cronquist (1981)를 반영한 GVPK (Park, 2007)와 비교하여 APGII (2003)에서 많은 변화가 있 었던 Liliaceae s. l. 내의 국내 속들의 재조합을 정리한 바 있 는데, 본 연구에서는 국내 전체 속들을 APG III (APG, 2009) 와 비교하였다. 그 결과 과의 이동이 있는 속들은 120 속으 로 파악되었다(Table 4). 또한 Cronquist (1981)에 비교하여 APG III (APG, 2009)에서 속이 재조합되어 분류군 인식의 변화가 있는 속들은 22속으로 파악되었다(Table 5).

Table 4. Genera of Cronquist (1981) of which familial positions are changed in APG III (APG, 2009).

\begin{tabular}{|c|c|c|c|c|c|}
\hline \multicolumn{4}{|c|}{ Cronquist (1981) } & \multicolumn{2}{|c|}{ APG III (APG, 2009) } \\
\hline Family & Family (Korean) & Genus & Genus (Korean) & Family & Family (Korean) \\
\hline Aceraceae & 단풍나무과 & Acer & 단풍나무속 & Sapindaceae & 무환자나무과 \\
\hline Agavaceae & 용설란과 & Agave & 용설란속 & Asparagaceae & 비짜루과 \\
\hline Agavaceae & 용설란과 & Yucca & 유카속 & Asparagaceae & 비짜루과 \\
\hline Alangiaceae & 박쥐나무과 & Alangium & 박쥐나무속 & Cornaceae & 층층나무과 \\
\hline Apiaceae & 산형과 & Hydrocotyle & 피막이속 & Araliaceae & 두릅나무과 \\
\hline Asclepiadaceae & 박주가리과 & Cynanchum & 백미꽃속 & Apocynaceae & 협죽도과 \\
\hline Asclepiadaceae & 박주가리과 & Marsdenia & 나도은조롱속 & Apocynaceae & 협죽도과 \\
\hline Asclepiadaceae & 박주가리과 & Metaplexis & 박주가리속 & Apocynaceae & 협죽도과 \\
\hline Asclepiadaceae & 박주가리과 & Tylophora & 왜박주가리속 & Apocynaceae & 협죽도과 \\
\hline Aucubaceae & 식나무과 & Aucuba & 식나무속 & Garryaceae & 가리아과 \\
\hline Callirichaceae & 별이끼과 & Callitriche & 별이끼속 & Plantaginaceae & 질경이과 \\
\hline Capparaceae & 풍접초과 & Cleome & 풍접초속 & Cleomaceae & 풍접초과 \\
\hline Celtidaceae & 팽나무과 & Aphananthe & 푸조나무속 & Cannabaceae & 삼과 \\
\hline Celtidaceae & 팽나무과 & Celtis & 팽나무속 & Cannabaceae & 삼과 \\
\hline Chenopodiaceae & 명아주과 & Atriplex & 갯능쟁이속 & Amaranthaceae & 비름과 \\
\hline Chenopodiaceae & 명아주과 & Axyris & 나도댑싸리속 & Amaranthaceae & 비름과 \\
\hline Chenopodiaceae & 명아주과 & Beta & 근대속 & Amaranthaceae & 비름과 \\
\hline Chenopodiaceae & 명아주과 & Chenopodium & 명아주속 & Amaranthaceae & 비름과 \\
\hline Chenopodiaceae & 명아주과 & Corispermum & 호모초속 & Amaranthaceae & 비름과 \\
\hline Chenopodiaceae & 명아주과 & Kochia & 댑싸리속 & Amaranthaceae & 비름과 \\
\hline Chenopodiaceae & 명아주과 & Salicornia & 퉁퉁마디속 & Amaranthaceae & 비름과 \\
\hline Chenopodiaceae & 명아주과 & Salsola & 수송나물속 & Amaranthaceae & 비름과 \\
\hline Chenopodiaceae & 명아주과 & Spinacia & 시금치속 & Amaranthaceae & 비름과 \\
\hline Chenopodiaceae & 명아주과 & Suaeda & 나문재속 & Amaranthaceae & 비름과 \\
\hline Clusiaceae & 물레나물과 & Hypericum & 물레나물속 & Hypericaceae & 물레나물과 \\
\hline Clusiaceae & 물레나물과 & Triadenum & 물고추나물속 & Hypericaceae & 물레나물과 \\
\hline Diervillaceae & 병꽃나무과 & Weigela & 병꽃나무속 & Caprifoliaceae & 인동과 \\
\hline Dipsacaceae & 산토끼꽃과 & Dipsacus & 산토끼꽃속 & Caprifoliaceae & 인동과 \\
\hline Dipsacaceae & 산토끼꽃과 & Scabiosa & 체꽃속 & Caprifoliaceae & 인동과 \\
\hline Empetraceae & 시로미과 & Empetrum & 시로미속 & Ericaceae & 진달래과 \\
\hline Euphorbiaceae & 대극과 & Securinega & 광대싸리속 & Phyllanthaceae & 여우주머니과 \\
\hline Euphorbiaceae & 대극과 & Phyllanthus & 여우주머니속 & Phyllanthaceae & 여우주머니과 \\
\hline Flacourtiaceae & 이나무과 & Idesia & 이나무속 & Salicaceae & 버드나무과 \\
\hline Flacourtiaceae & 이나무과 & Xylosma & 산유자나무속 & Salicaceae & 버드나무과 \\
\hline
\end{tabular}


Table 4. Continued.

\begin{tabular}{|c|c|c|c|c|c|}
\hline Fumariaceae & 현호색과 & Corydalis & 현호색속 & Papaveraceae & 양귀비과 \\
\hline Fumariaceae & 현호색과 & Dicentra & 금낭화속 & Papaveraceae & 양귀비과 \\
\hline Fumariaceae & 현호색과 & Adlumia & 줄꽃주머니속 & Papaveraceae & 양귀비과 \\
\hline Hippocastanaceae & 칠엽수과 & Aesculus & 칠엽수속 & Sapindaceae & 무환자나무과 \\
\hline Illiciaceae & 붓순나무과 & Illicium & 붓순나무속 & Schisandraceae & 오미자과 \\
\hline Lemnaceae & 개구리밥과 & Lemna & 좀개구리밥속 & Araceae & 천남성과 \\
\hline Lemnaceae & 개구리밥과 & Spirodela & 개구리밥속 & Araceae & 천남성과 \\
\hline Lemnaceae & 개구리밥과 & Wolffia & 분개구리밥속 & Araceae & 천남성과 \\
\hline Liliaceae & 백합과 & Aletris & 쥐꼬리풀속 & Nartheciaceae & 나르씨시움과 \\
\hline Liliaceae & 백합과 & Allium & 부추속 & Amaryllidaceae & 수선화과 \\
\hline Liliaceae & 백합과 & Chionographis & 실꽃풀속 & Melanthiaceae & 멜란지움과 \\
\hline Liliaceae & 백합과 & Disporum & 애기나리속 & Colchicaceae & 콜치움과 \\
\hline Liliaceae & 백합과 & Heloniopsis & 처녀치마속 & Melanthiaceae & 멜란지움과 \\
\hline Liliaceae & 백합과 & Metanarthecium & 칠보치마속 & Nartheciaceae & 나르씨시움과 \\
\hline Liliaceae & 백합과 & Paris & 삿갓나물속 & Melanthiaceae & 멜란지움과 \\
\hline Liliaceae & 백합과 & Trillium & 연영초속 & Melanthiaceae & 멜란지움과 \\
\hline Liliaceae & 백합과 & Veratrum & 여로속 & Melanthiaceae & 멜란지움과 \\
\hline Liliaceae & 백합과 & Zigadenus & 나도여로속 & Melanthiaceae & 멜란지움과 \\
\hline Liliaceae & 백합과 & Tofieldia & 꽃장포속 & Tofieldiaceae & 꽃장포과 \\
\hline Liliaceae & 백합과 & Hemerocallis & 원추리속 & Asphodelaceae & 에스포델러스과 \\
\hline Liliaceae & 백합과 & Asparagus & 비짜루속 & Asparagaceae & 비짜루과 \\
\hline Liliaceae & 백합과 & Hosta & 비비추속 & Asparagaceae & 비짜루과 \\
\hline Liliaceae & 백합과 & Scilla & 무릇속 & Asparagaceae & 비짜루과 \\
\hline Liliaceae & 백합과 & Smilacina & 솜대속 & Asparagaceae & 비짜루과 \\
\hline Liliaceae & 백합과 & Convallaria & 은방울꽃속 & Asparagaceae & 비짜루과 \\
\hline Liliaceae & 백합과 & Polygonatum & 둥글레속 & Asparagaceae & 비짜루과 \\
\hline Liliaceae & 백합과 & Maianthemum & 두루미꽃속 & Asparagaceae & 비짜루과 \\
\hline Liliaceae & 백합과 & Liriope & 맥문동속 & Asparagaceae & 비짜루과 \\
\hline Liliaceae & 백합과 & Ophiopogon & 맥문아재비속 & Asparagaceae & 비짜루과 \\
\hline Liliaceae & 백합과 & Aspidistra & 엽란속 & Asparagaceae & 비짜루과 \\
\hline Linnaeaceae & 린네풀과 & Linnaea & 린네풀속 & Caprifoliaceae & 인동과 \\
\hline Linnaeaceae & 린네풀과 & Zabelia & 줄댕강나무속 & Caprifoliaceae & 인동과 \\
\hline Monotropaceae & 수정난풀과 & Monotropa & 수정난풀속 & Ericaceae & 진달래과 \\
\hline Monotropaceae & 수정난풀과 & Monotropastrum & 나도수정초속 & Ericaceae & 진달래과 \\
\hline Myrsinaceae & 자금우과 & Ardisia & 자금우속 & Primulaceae & 앵초과 \\
\hline Najadaceae & 나자스말과 & Najas & 나자스말속 & Hydrocharitaceae & 자라풀과 \\
\hline Parmassoaceae & 물매화과 & Parnassia & 물매화속 & Celastraceae & 노박덩굴과 \\
\hline Punicaceae & 석류나무과 & Punica & 석류나무속 & Lythraceae & 부처꽃과 \\
\hline Pyrolaceae & 노루발과 & Chimaphila & 매화노루발속 & Ericaceae & 진달래과 \\
\hline Pyrolaceae & 노루발과 & Moneses & 홀꽃노루발속 & Ericaceae & 진달래과 \\
\hline Pyrolaceae & 노루발과 & Orthilia & 새끼노루발속 & Ericaceae & 진달래과 \\
\hline Pyrolaceae & 노루발과 & Pyrola & 노루발속 & Ericaceae & 진달래과 \\
\hline Ruppiaceae & 줄말과 & Ruppia & 줄말속 & Potamogetonaceae & 가래과 \\
\hline Scrophulariaceae & 현삼과 & Antirrhinum & 금어초속 & Plantaginaceae & 질경이과 \\
\hline Scrophulariaceae & 현삼과 & Centranthera & 성주풀속 & Orobanchaceae & 열당과 \\
\hline Scrophulariaceae & 현삼과 & Digitalis & 디기탈리스속 & Plantaginaceae & 질경이과 \\
\hline Scrophulariaceae & 현삼과 & Dopatrium & 등에풀속 & Plantaginaceae & 질경이과 \\
\hline
\end{tabular}


Table 4. Continued.

\begin{tabular}{|c|c|c|c|c|c|}
\hline Scrophulariaceae & 현삼과 & Euphrasia & 좁쌀풀속 & Orobanchaceae & 열당과 \\
\hline Scrophulariaceae & 현삼과 & Gratiola & 큰고추풀속 & Plantaginaceae & 질경이과 \\
\hline Scrophulariaceae & 현삼과 & Limnophila & 구와말속 & Plantaginaceae & 질경이과 \\
\hline Scrophulariaceae & 현삼과 & Linaria & 해란초속 & Plantaginaceae & 질경이과 \\
\hline Scrophulariaceae & 현삼과 & Melampyrum & 꽃며느리밥풀속 & Orobanchaceae & 열당과 \\
\hline Scrophulariaceae & 현삼과 & Microcarpaea & 진흙풀속 & Phrymaceae & 파리풀과 \\
\hline Scrophulariaceae & 현삼과 & Mimulus & 물꽈리아재비속 & Phrymaceae & 파리풀과 \\
\hline Scrophulariaceae & 현삼과 & Omphalotrix & 쌀파도풀속 & Orobanchaceae & 열당과 \\
\hline Scrophulariaceae & 현삼과 & Pedicularis & 송이풀속 & Orobanchaceae & 열당과 \\
\hline Scrophulariaceae & 현삼과 & Phtheirospermum & 나도송이풀속 & Orobanchaceae & 열당과 \\
\hline Scrophulariaceae & 현삼과 & Rehmannia & 지황속 & Orobanchaceae & 열당과 \\
\hline Scrophulariaceae & 현삼과 & Siphonostegia & 절국대속 & Orobanchaceae & 열당과 \\
\hline Scrophulariaceae & 현삼과 & Veronica & 개불알풀속 & Plantaginaceae & 질경이과 \\
\hline Scrophulariaceae & 현삼과 & Veronicastrum & 냉초속 & Plantaginaceae & 질경이과 \\
\hline Scrophulariaceae & 현삼과 & Paulownia & 오동나무속 & Paulowniaceae & 오동나무과 \\
\hline Scrophulariaceae & 현삼과 & Lindernia & 밭둑외풀속 & Linderniaceae & 밭둑외풀과 \\
\hline Scrophulariaceae & 현삼과 & Mazus & 주름잎속 & Phrymaceae & 파리풀과 \\
\hline Scrophulariaceae & 현삼과 & Deinostema & 진땅고추풀속 & Plantaginaceae & 질경이과 \\
\hline Scrophulariaceae & 현삼과 & Pseudolysimachion & 꼬리풀속 & Plantaginaceae & 질경이과 \\
\hline Sparganiaceae & 흑삼릉과 & Sparganium & 흑삼릉속 & Typhaceae & 부들과 \\
\hline Sterculiaceae & 벽오동과 & Firmiana & 벽오동속 & Malvaceae & 아욱과 \\
\hline Sterculiaceae & 벽오동과 & Melochia & 불암초속 & Malvaceae & 아욱과 \\
\hline Theaceae & 차나무과 & Cleyera & 비쭈기나무속 & Pentaphylacaceae & 펜타필락스과 \\
\hline Theaceae & 차나무과 & Eurya & 사스레피나무속 & Pentaphylacaceae & 펜타필락스과 \\
\hline Theaceae & 차나무과 & Ternstroemia & 후피향나무속 & Pentaphylacaceae & 펜타필락스과 \\
\hline Tiliaceae & 피나무과 & Corchoropsis & 까치깨속 & Malvaceae & 아욱과 \\
\hline Tiliaceae & 피나무과 & Corchorus & 황마속 & Malvaceae & 아욱과 \\
\hline Tiliaceae & 피나무과 & Grewia & 장구밥나무속 & Malvaceae & 아욱과 \\
\hline Tiliaceae & 피나무과 & Tilia & 피나무속 & Malvaceae & 아욱과 \\
\hline Tiliaceae & 피나무과 & Triumfetta & 고슴도치풀속 & Malvaceae & 아욱과 \\
\hline Trapaceae & 마름과 & Trapa & 마름속 & Lythraceae & 부처꽃과 \\
\hline Valerianaceae & 마타리과 & Patrinia & 마타리속 & Caprifoliaceae & 인동과 \\
\hline Valerianaceae & 마타리과 & Valeriana & 쥐오줌풀속 & Caprifoliaceae & 인동과 \\
\hline Verbenaceae & 마편초과 & Callicarpa & 작살나무속 & Lamiaceae & 꿀풀과 \\
\hline Verbenaceae & 마편초과 & Caryopteris & 층꽃나무속 & Lamiaceae & 꿀풀과 \\
\hline Verbenaceae & 마편초과 & Clerodendrum & 누리장나무속 & Lamiaceae & 꿀풀과 \\
\hline Verbenaceae & 마편초과 & Vitex & 순비기나무속 & Lamiaceae & 꿀풀과 \\
\hline Viburnaceae & 인동과 & Viburnum & 산분꽃나무속 & Adoxaceae & 연복초과 \\
\hline Zannichelliaceae & 뿔말과 & Zannichellia & 뿔말속 & Potamogetonaceae & 가래과 \\
\hline
\end{tabular}

목명과 과명의 국문화 방법이 비록 학명과 같은 절대적 인 법칙이 존재하는 것은 아니지만 학명과 마찬가지로 하 위 기준 분류군을 토대로 한 국문화 방법은 다른 방법들 보 다 안정성이 높아 미래의 혼란을 방지할 수 있을 것이다. 본 연구에서 새롭게 제시한 목과 과의 국명들은 2-3에 근거 하여 기준속을 발음한 것에 근거한 것이지만 향후 국내에 서 새롭게 많이 회자되는 종들에 대해서는 궁극적으로 그
특성을 반영한 한글 이름이 제시되어야 할 것이다. 한글 이 름의 새로운 작명에 대해서는 해당 기준속에 속하는 식물 의 1) 원어 이름을 우리나라말로 번역을 하거나 2) 기존의 우리나라 종의 이름에 해당 분류군의 특성 또는 지역적 의 미의 어구를 첨가하는 방법을 생각할 수 있다. 본 연구에서 제안한 목과 과에 대한 국명들은 향후 전문가 그룹의 논의 를 거쳐 공표될 국가표준안의 기초를 제공할 것이다. 
Table 5. Genera of Cronquist system (1981) combined with other genera in the APG III (APG, 2009).

\begin{tabular}{|c|c|c|c|c|}
\hline \multicolumn{4}{|c|}{ "Cronquist (1981) } & \multirow{2}{*}{$\frac{\text { APG III (APG, 2009) }}{\text { Accepted Name }}$} \\
\hline Family & Family (Korean) & Genus & Genus (Korean) & \\
\hline Anacardiaceae & 옻나무과 & Toxicodendron & 옻나무속 & Rhus \\
\hline Asteraceae & 국화과 & Rhaponticum & 뻐꾹채속 & Leuzea \\
\hline Asteraceae & 국화과 & Dracopsis & 천인국아재비속 & Rudbeckia \\
\hline Brassicaceae & 십자화과 & Arabidopsis & 애기장대속 & Arabis \\
\hline Ericaceae & 진달래과 & Ledum & 백산차속 & Rhododendron \\
\hline Gentianaceae & 용담과 & Anagallidium & 대성쓴풀속 & Swertia \\
\hline Poaceae & 벼과 & Cleistogenes & 대새풀속 & Kengia \\
\hline Lauraceae & 녹나무과 & Machilus & 후박나무속 & Persea \\
\hline Liliaceae & 백합과 & Lloydia & 개감채속 & Gagea \\
\hline Liliaceae & 백합과 & Smilacina & 솜대속 & Maianthemum \\
\hline Moraceae & 뽕나무과 & Cudrania & 꾸지뽕나무속 & Maclura \\
\hline Papaveraceae & 양귀비과 & Coreanomecon & 메미꽃속 & Chelidonium \\
\hline Poaceae & 벼과 & Asperella & 수염개밀속 & Hystrix \\
\hline Poaceae & 벼과 & Moliniopsis & 진퍼리새속 & Molinia \\
\hline Ranunculaceae & 미나리아재비과 & Megaleranthis & 모데미풀속 & Eranthis \\
\hline Rosaceae & 장미과 & Pourthiaea & 윤노리나무속 & Photinia \\
\hline Rosaceae & 장미과 & Aria & 팥배나무속 & Sorbus \\
\hline Solanaceae & 가지과 & Physaliastrum & 가시꽈리속 & Leucophysalis \\
\hline Staphyleaceae & 고추나무과 & Euscaphis & 말오줌때속 & Staphylea \\
\hline Apiaceae & 산형과 & Libanotis & 털기름나물속 & Seseli \\
\hline Apiaceae & 산형과 & Ostericum & 묏미나리속 & Angelica \\
\hline Urticaceae & 쐐기풀과 & Pellionia & 펠리온나무속 & Elatostema \\
\hline
\end{tabular}

\section{사 사}

이 논문은 2014년도 성신여자대학교 학술연구조성비 지원에 의하여 연구되었음을 밝힙니다.

\section{Literature Cited}

APG (The Angiosperm Phylogeny Group). 1998. An ordinal classification for the families of flowering plants. Annals of Missouri Botanical Garden 85: 531-553.

APG (The Angiosperm Phylogeny Group). 2003. An update of the angiosperm phylogeny group classification for the orders and families of flowering plants: APG II. Botanical Journal of Linnean Society 141: 399-436.

APG (The Angiosperm Phylogeny Group). 2009. An update of the angiosperm phylogeny group classification for the orders and families of flowering plants: APG III. Botanical Journal of Linnean Society 161: 105-121.

Chung, T. H. 1957. Korean Flora. Kyo-yuk publishing Co., Seoul. (in Korean)

Chung T. H., Do B. S., Lee D. B. and Lee H. J. 1937. Cho-SunSik-Mul-Hyang-Myong-Jip. Chosen Hist. Soc., Seoul. (in Korean)

Chung T. H., Do B. S. and Sim H. J. 1949. Nomina Plantarum Koreanum. Chosen Bio. Soc., Seoul. (in Korean)

Cronquist, A. 1981. An Integrated System of Classification of Flowering Plants. Columbia Univ. Press, New York.

Englar A. 1964. Syllabus der Pflanzenfamilien. H. Melchior (ed.), $12^{\text {th }}$ ed., vol 2. Borntraeger, Berlin.

Judd, W. S., C. S. Campbell, E. A. Kellogg, P. F. Stevens, and M. J. Donoghue. 2008. Plant Systematics-A Phylogentic Approach. $2^{\text {nd }}$ ed. Sinauer Associates, Sunderland.

Kim, K.-J., Y.-D. Kim, J.-H. Kim, S.-J. Park, C.-W. Park, B.-Y. Sun, K.-O. Yoo, B.-H. Choi and S. T. Kim. 2008. Phylogenetic classification of Korean vascular flora according to the recent APG classification system. Korean Journal of Plant Taxonomy 38: 197-222. (in Korean)

Korea National Arboretum. 2014. A Synonymic List of Vascular 
Plants in Korea (web-version of June 30, 2014), Retrieved June 2014, from http://www.nature.go.kr/newkfsweb/kfs/idx/ SubIndex.do?orgId=kpni\&mn=KFS 29.

Korea National Arboretum and The Plant Taxonomic Society of Korea. 2007. A Synonymic List of Vascular Plants in Korea. Korea National Arboretum. Pocheon. (in Korean)

Lee, T. B. 1989. Illustrated Flora of Korea. Hyang-mun publishing Co., Seoul. (in Korean)

Lee, W. T. 1996a. Colored Standard Illustrations of Korean Plants. Academy publishing Co., Seoul. (in Korean)

Lee, W. T. 1996b. Lineamenta Florae Koreae. Academy publishing Co., Seoul. (in Korean)

Lee, Y. N. 1996. Flora of Korea. Kyo-hak Publishing Co., Seoul. (in Korean)
National Institute of Biological Resources. 2011. National List of Species of Korea. Vascular Plants. Korean Institute of Biological Resources, Incheon. (in Korean)

Park, C.-W. (ed.). 2007. The genera of vascular plants of Korea. Flora of Korea Editorial Committee. Academy Publ. Co., Seoul. (in Korean)

Pak. M. K. 1949. An Enumeration of Korean Plants. Ministry of Education. Seoul. (in Korean)

Simpson, M. G. 2010. Plant Systematics. $2^{\text {nd }}$ ed. Elsevier, New York.

Stevens, P. F. 2015. Angiosperm Phylogeny Website (version 14). Retrieved April 2015, from http://www.mobot.org/MOBOT/ research/APweb/. 